\title{
Electron spin resonance dating of optically bleached quartz grains from the Middle Palaeolithic site of Cuesta de la Bajada (Spain) using the multiple centres approach
}

\author{
M. Duval ${ }^{\text {a, *, L. Arnold }}{ }^{\text {b }}$, V. Guilarte ${ }^{\text {a }}$, M. Demuro ${ }^{\text {b }}$, M. Santonja ${ }^{\text {a }}$, A. Pérez-Gonzalez $^{\text {a }}$ \\ a Centro Nacional de Investigación Sobre la Evolución Humana (CENIEH), Paseo de Atapuerca, 3, 09002 Burgos, Spain \\ b School of Physical Sciences, Environment Institute, Institute for Photonics and Advanced Sensing (IPAS), University of Adelaide, North Terrace Campus, Adelaide, SA 5005, \\ Australia
}

\section{A R T I C L E I N F O}

Article history:

Received 5 July 2016

Received in revised form 20 September 2016

Accepted 26 September 2016

Available online $\mathrm{xxx}$

\begin{abstract}
A B S T R A C T
Electron spin resonance (ESR) dating of optically bleached quartz grains was performed on three sediment samples collected from the Middle Palaeolithic site of Cuesta de la Bajada (Spain). A standard multiple grain and multiple aliquot additive dose procedure was employed, and both the $\mathrm{Al}$ and $\mathrm{Ti}$ centres were measured as part of the multiple centres approach.

ESR age estimates obtained for the three samples indicate that the $\mathrm{Al}$ centre provides a maximum possible chronology; use of the Ti centres show that the Al signal was likely not systematically reset to its residual level during sediment transportation. A direct comparison between ESR ages based on the Ti centres and single grain optically stimulated luminescence (OSL) ages from samples collected nearby shows broadly consistent results. The Ti-H centre also appears to provide suitable chronologies for at least two of the three Middle Pleistocene samples studied here. Surprisingly, the only sample showing consistent ESR ages between the Al and Ti centres appears to be overestimated in comparison with the Ti-centre and OSL ages derived from the other two samples. This indicates either incomplete bleaching of both the $\mathrm{Al}$ and Ti centres for this sample, or unexpected impacts of other sources of $\mathrm{D}_{\mathrm{e}}$ uncertainty, such as multi-grain averaging effects. The ESR dating results overall indicate that the archaeological sequence of Cuesta de la Bajada CB-3 is most likely correlated to either MIS 7 or 9.
\end{abstract}

(C) 2016 Published by Elsevier Ltd.

\section{Introduction}

First proposed by Toyoda et al. (2000), the "Multiple Centres" (MC) approach has undoubtedly been a major breakthrough in the development of the Electron Spin Resonance (ESR) dating method applied to optically bleached quartz grains. Though the few works involving the simultaneous dating of both $\mathrm{Al}$ and Ti centres have provided very encouraging results (e.g. Burdette et al., 2013; Tissoux et al., 2007, 2008; Rink et al., 2007), many ESR dating studies remain nevertheless focused on the analysis of a single centre (e.g. Voinchet et al., 2013; Liu et al., 2013). Duval et al. (2015a, 2015b) recently highlighted the importance of using the MC approach to date Early Pleistocene fluvial deposits, by providing the first numerical ages for the highest terrace deposits of the Alcanadre River in the Ebro basin (Spain). Building on these promising results, it is now crucial to further test the MC approach on late Middle Pleistocene deposits, where comparative age control could be provided by another numerical dating method. For this purpose, optically stimulated luminescence (OSL) is undoubtedly the best candidate; both OSL and ESR dating may be applied to the same material (quartz grains) and both methods date the same resetting event (i.e. the last sunlight exposure), thereby

\footnotetext{
* Corresponding author.

Email address: mathieu.duval@cenieh.es (M. Duval)
}

minimising the potential bias that may arise from the use of different dating approaches. So far, these methods have rarely been subject to cross comparisons at the same locality. OSL is usually employed for deposits whose chronology does not exceed the late Middle Pleistocene time range (200-300 ka), while ESR is primarily used to date much older deposits, given the higher radiation saturation thresholds of the signals (e.g. Cordier et al., 2012). Only a few ESR/OSL comparison studies have been published, and the results have been largely inconclusive. For example, the chronology of the deposits analysed by Burdette et al. (2013) was beyond the applicability of OSL dating, while Tissoux et al. (2010) were not able to derive reliable ESR results. In contrast, Beerten et al. (2006) showed that analysis of the Ti centres using a Multiple Aliquot Regenerative dose (MAR) method could provide somewhat consistent results with Single Aliquot Regenerative dose (SAR) OSL dating. However, in this specific case the Al centre was not measured as part of a MC approach.

In this context, the Middle Pleistocene archaeological site of Cuesta de la Bajada (Spain) provides a useful opportunity for independently and thoroughly testing standard ESR and OSL procedures, as well as for assessing new approaches in both palaeodosimetric methods. We have undertaken a combined ESR-OSL dating study of this site using closely paired sediment samples. The present work presents the details of the ESR dating study, whose initial results have been partly summarised in Santonja et al. (2014); while the companion paper by Arnold et al. (2016) focuses on the OSL dating results 
and the potential to obtain extended-range OSL chronologies using quartz 'supergrains'.

\section{ESR dating of optically bleached quartz grains}

\subsection{Optical bleaching characteristics of Al and Ti centres}

In order to evaluate the bleaching kinetics of each centre in different quartz samples, we first carried out a laboratory bleaching experiment with a UVACUBE 400 (Dr Honle) sunlight simulator connected to a SOL 500 unit and equipped with a S lamp that reproduces the sunlight spectrum. A $\mathrm{H} 2$ filter was also added in order to remove UVC rays, as Tissoux et al. (2007) previously showed that the decrease of the ESR signal for both $\mathrm{Al}$ and $\mathrm{Ti}$ centres was mostly due to UVA and UVB. The manufacturer specification indicates that illumination intensity is about 7 times greater than natural daylight (commercial information available at http://www.eleco-produits.fr/fileadmin/flyer/ SoSi_sun_simulation_A4_e.pdf). Two quartz samples (FN1001 and MOR1101) from very different sedimentary environments were selected: MOR1101 was collected from the Middle Pleistocene fluvial deposits at Morée-Villeprovert, France (Despriée et al., 2011), while FN1001 was sampled within the Early Pleistocene fluvio-lacustrine sediment of Fuente Nueva-3 site, Spain (Duval et al., 2012). These two samples were divided into 26 aliquots and laboratory bleached for up to $1176 \mathrm{~h}$. The depletion of the ESR intensities for both the $\mathrm{Al}$ and $\mathrm{Ti}$ centres (Ti-H, option $\mathrm{C}$ and $\mathrm{Ti}-\mathrm{Li}$, option $\mathrm{E}$; see further details in Section 4) was assessed over repeated measurements of each aliquot and the results are shown in Fig. 1.

As expected, our results show that the paramagnetic centres have very different bleaching kinetics. The $\mathrm{Al}$ signal reaches a plateau at around $860 \mathrm{~h}$ of illumination for both samples, i.e. an equivalent of $>8$ months of natural continuous illumination. The residual ESR intensity represents $81 \%$ and $52 \%$ of the natural ESR intensity for samples FN1001 and MOR1101, respectively. Such a difference is not surprising as the magnitude of the bleachable ESR signal component (defined as the relative difference between the intensity of the natural aliquot and that of the bleached one) is known to be sample dependent, although the values are usually quite homogeneous for samples from a given site (see examples in Duval, 2008; Tissoux et al., 2012). For example, at Cuesta de la Bajada, this parameter varies within a very narrow range of between $54.3 \%$ and $56.5 \%$ (Table 1 ).

In contrast to the Al-centre, the Ti-H signal is much more light sensitive and is fully reset in only a few hours, i.e. $<4 \mathrm{~h}$ for sample MOR1101 and $<1 / 2 \mathrm{~h}$ for FN1001, which roughly correspond to
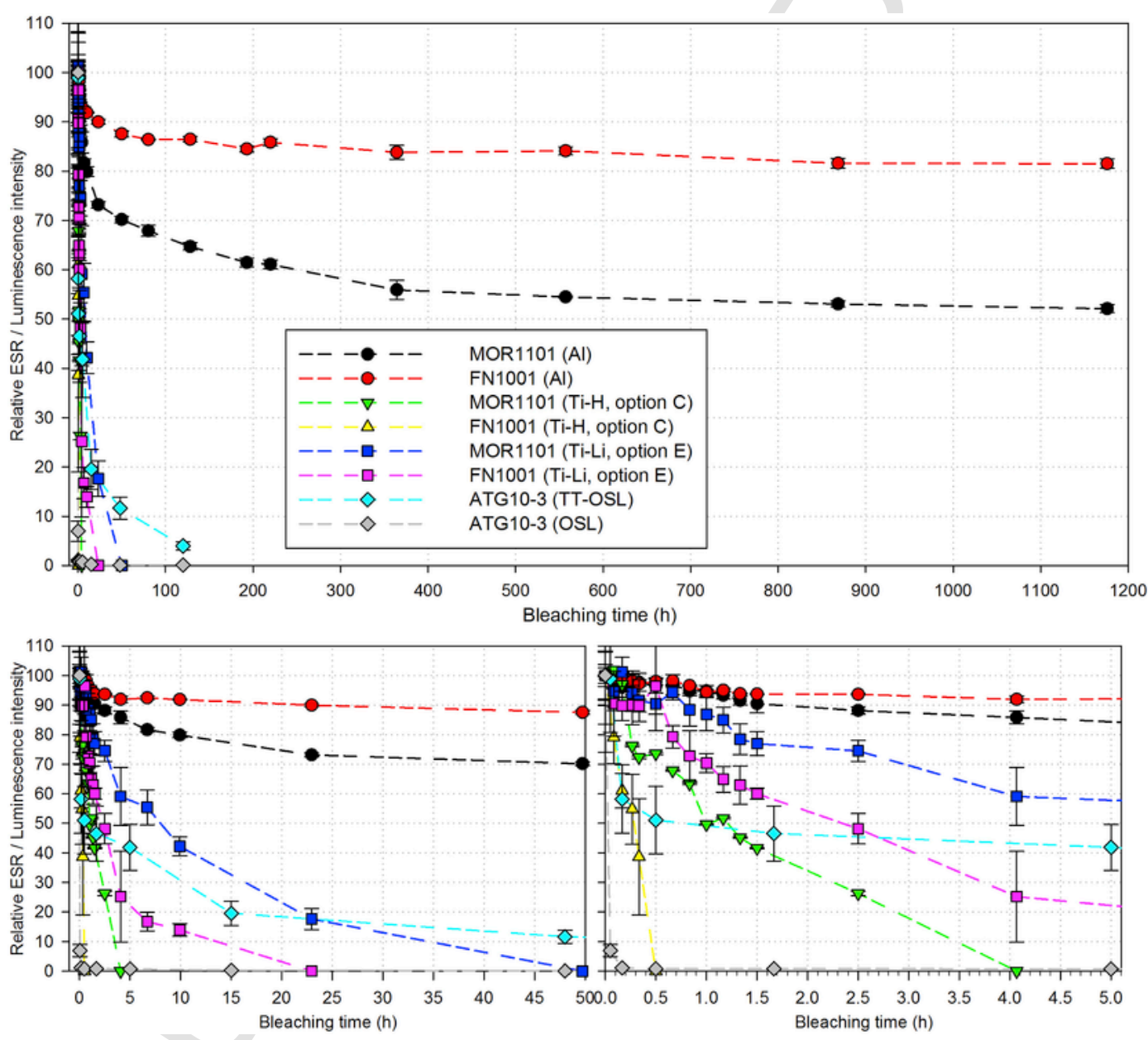

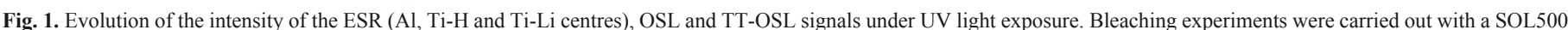

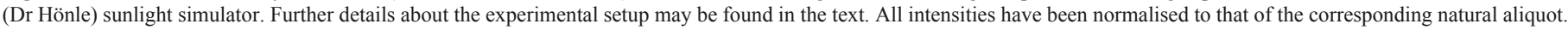

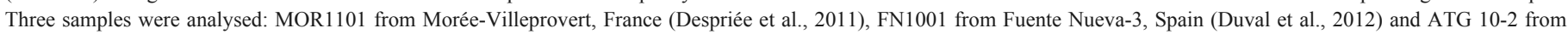

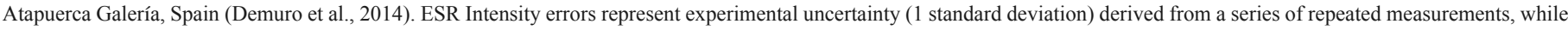

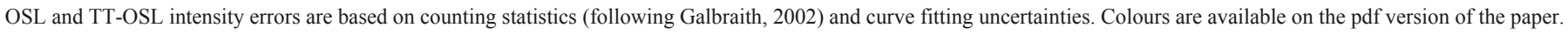


Table 1

Summary of the main features usually observed for the signals of the three paramagnetic centres (Al, Ti-Li and Ti-H) in a given sample (from Rixhon et al., 2016). Based on the authors' experience, relative characterisation is provided (although some samples may sometimes show different features $):(+++)=$ high,$(++)=$ medium,$(+)=$ low .

\begin{tabular}{llll}
\hline & Al centre & Ti-Li centre & Ti-H centre \\
\hline $\begin{array}{l}\text { Signal-to-Noise } \\
\text { ratio (S/N) }\end{array}$ & +++ & ++ & + \\
$\begin{array}{c}\text { Precision of the } \\
\text { measurements }\end{array}$ & +++ & ++ & + \\
$\begin{array}{c}\text { Dose response } \\
\text { curve }\end{array}$ & $\begin{array}{l}\text { No apparent } \\
\text { saturation at } \\
\text { high doses }\end{array}$ & $\begin{array}{l}\text { Non-monotonic } \\
\text { behaviour } \\
\text { (maximum intensity } \\
(>60 \mathrm{kGy})\end{array}$ & $\begin{array}{l}\text { Non-monotonic } \\
\text { behaviour } \\
\text { (maximum intensity } \\
\sim 3-8 \mathrm{kGy})\end{array}$ \\
$\begin{array}{l}\text { Bleaching kinetics } \\
\text { (speed) }\end{array}$ & + & ++ & +++ \\
$\begin{array}{l}\text { Residual ESR } \\
\text { intensity } \\
\text { (unbleachable }\end{array}$ & Yes & No & No \\
component) & & & \\
\hline
\end{tabular}

$<28 \mathrm{~h}$ and $<3.5 \mathrm{~h}$ of natural sunlight, respectively. By comparison, the Ti-Li centre (option E, Duval and Guilarte, 2015) shows slower bleaching kinetics and full resetting is achieved by $<50 \mathrm{~h}$ for MOR1101 and $<23 \mathrm{~h}$ for FN1001, i.e. approximately $<14.6$ days and $<6.7$ days of natural sunlight. These results indicate that the bleaching kinetics of a given Ti centre may vary by a factor of $>2$ depending on the sample considered, thus illustrating the existing variability in natural quartz samples.

To summarise, the two samples show the same trend in terms of bleaching kinetics, with the $\mathrm{Al}$ and $\mathrm{Ti}-\mathrm{H}$ centres being the least and most light sensitive, respectively, and the Ti-Li yielding intermediary bleaching rates. These relative differences are consistent with those previously obtained by Tissoux et al. (2007) and Toyoda et al. (2000), even though their absolute bleaching rates cannot be directly compared with our data given differences in the experimental setup (see also Voinchet et al. (2003) and Walther and Zilles (1994) for comparison).

In order to compare the bleaching kinetics of the luminescence and ESR signals, an additional experiment was carried out using the same solar simulator setup: a series of 800-grain aliquots of ATG10-3 sample from Atapuerca Galería site, Spain (Demuro et al., 2014; Arnold et al., 2015), were bleached over increasing time periods of up to $120 \mathrm{~h}$ ( $n=3$ aliquots per time period). OSL and thermally transferred OSL (TT-OSL) signals were measured after each bleaching period using the instrumentation outlined in the companion paper (Arnold et al., 2016) and the multi-grain SAR TT-OSL procedure outlined by Arnold et al. (2013).

As expected, the OSL signal is optically depleted at a significantly faster rate than the ESR signals (Fig. 1): about $99 \%$ of the natural signal intensity is reset after only $10 \mathrm{~min}$. In comparison, the TT-OSL signal shows a similar bleaching rate to that of the Ti-H signal in the first $1.5 \mathrm{~h}$. Thereafter, the TT-OSL bleaching rate is more akin to that of the Ti-Li or the $\mathrm{Al}$ centre. After $120 \mathrm{~h}$ of UV-exposure, about $4 \%$ of the average natural TT-OSL signal intensity is still present in this quartz sample. However, the TT-OSL signal of one of the three measured aliquots was fully reset after $120 \mathrm{~h}$ of simulated daylight exposure. Complete resetting of the TT-OSL signal is therefore possible for at least some aliquots of sample ATG10-3. It is difficult to know from these data whether the average TT-OSL signal intensity of all measured aliquots would be completely zeroed after more extended bleaching periods (beyond $120 \mathrm{~h}$ ).
In this context, it is worth mentioning that a previous bleaching experiment performed on multiple grain aliquots from Huescar-1, Spain (Demuro et al., 2015), showed a TT-OSL residual intensity of $12 \%$ after 19 weeks of exposure to natural sunlight (see also discussion Section 4.2. in Demuro et al., 2015) . In contrast, a number of modern analogue and known age studies have shown that TT-OSL signals can be fully reset under natural conditions or at least bleached down to very low residuals (on the order of a few Gy or tens of Gy) under prolonged daylight exposure (e.g., Arnold et al., 2014, 2015). Single-grain TT-OSL studies have also revealed that multi-grain TT-OSL signals may be dominated by grains with unfavourable TT-OSL behaviours or that apparent TT-OSL age offsets and artificial residual doses may result from multi-grain averaging effects (Arnold et al., 2015; Arnold and Demuro, 2015). These complications should therefore be taken into consideration when interpreting TT-OSL bleaching rates from multi-grain aliquot solar simulator experiments.

Since single grain ESR dating is currently impractical on a routine basis (Beerten and Stesmans, 2006), the present comparisons focus on the multi-grain scale of analysis. The results in Fig. 1 suggest that the signals of the Ti-H and Ti-Li centres are zeroed at a faster or similar rate in comparison with the multi-grain TT-OSL signal. However, the potential for inter-sample variability in bleaching rates (as evident in Fig. 1) means it would be worthwhile confirming these pattern on other samples, and carrying out parallel ESR, OSL and TT-OSL bleaching comparisons on exactly the same samples.

Given the estimated time necessary to reset the ESR signals, especially for the $\mathrm{Al}$ centre ( $>8$ months of natural continuous illumination), one may reasonably question whether adequate bleaching can be realistically achieved during transportation in natural conditions. Empirical data show that this is possible, at least for some sites. For example, Voinchet et al. (2007) collected several modern sand samples along a downstream profile of the Creuse River (France), and showed that the Ti signals had been fully bleached and the Al signals had been reset down to their unbleachable residuals in less than $2.5 \mathrm{~km}$ of fluvial transport. Additionally, the ESR dating study of Vallparadís (Spain) yielded Al centre ESR ages that were consistent with independent age control spanning 0.78 and $0.99 \mathrm{Ma}$ (Duval et al., 2015a,b), thus indirectly supporting adequate resetting of the bleachable Al signal component prior to burial.

In assessing the likelihood of ESR quartz bleaching in nature, it may also be important to exert caution when converting solar simulator bleaching times into equivalent hours of natural sunlight exposure, simply because laboratory bleaching conditions are quite different from natural conditions. For instance, most bleaching experiments are carried out on prepared (purified, etched and well-sorted) quartz samples as opposed to polymineral, unsorted grain mixtures with surface coatings. Natural optical bleaching rates of quartz samples will also be influenced by factors such as the altitude (e.g. Gao et al., 2009), latitudinal variations in UV intensities, cloud cover, transport medium, and depth below water surface. In addition, Liu and Grün (2011) recently showed that mechanical processes of surface abrasion may eventually lead to some ESR signal resetting as well.

In conclusion, our laboratory bleaching experiments provide some useful information about the relative differences in bleaching sensitivity for each centre but any further extrapolation regarding the broader reliability of ESR dating results would be speculative, as there are most likely several underlying phenomena involved in the bleaching processes that are poorly represented in the laboratory. Additionally, as with OSL and TT-OSL dating, multi-grain averaging effect might have a non-negligible impact on our data; although this remains difficult to quantify for ESR dating signals. 


\subsection{The multiple centres approach: a brief overview}

The significant difference in bleaching rates between the $\mathrm{Al}$ and Ti centres led Toyoda et al. (2000) to first propose the MC approach. This method is based on the assumption that all the centres measured in a given quartz sample should theoretically provide similar dose estimates. Hence, if the $\mathrm{Al}$ centre yields a significantly higher $\mathrm{D}_{e}$ value, then this is most likely due to incomplete bleaching of this signal (i.e. the signal was not reset to its residual, unbleachable intensity). Irrespective, the slow bleaching kinetics of the Al signal mean that this centre should be considered by default to only provide maximum possible age estimates; i.e., the true age of the deposits is taken as being either similar to, or younger than, the measured ESR age. If the Ti age estimate is significantly younger than its $\mathrm{Al}$ equivalent, then the former should be considered as a best estimation of the chronology of the deposits (Duval et al., 2015a,b).

Some authors have recently suggested that the consistency of the $\mathrm{D}_{\mathrm{E}}$ values derived from each centre may be used as a criterion for considering an ESR age estimate as accurate (Rink et al., 2007). However, such generalisations have recently been shown to be invalid by Duval et al. (2015a, 2015b), since other sources of uncertainties may contribute to the age calculations; particularly for the dose rate evaluation, which may strongly impact the accuracy of the final dating results.

Given the major advantage offered by the Ti centres in terms of bleaching kinetics, one may reasonably question the interest of measuring the Al signal. However, the two centres offer useful, complementary properties for dating purposes (see an overview in Table 1). Since aluminum is the most abundant trace element in $\alpha$ quartz (Preusser et al., 2009), it is possible to measure the ESR signal associated with the Al paramagnetic centre in all samples. The ESR signal of the $\mathrm{Al}$ centre is also relatively easy to measure at low temperature given its high intensity. Repeatable measurements can therefore be performed, and goodness-of-fit tends to be very high. In contrast, the Ti centres are sometimes absent from quartz samples and their weaker intensities make it more complicated to achieve repeatable measurements (Duval and Guilarte, 2015). Goodness-of-fit is usually not as good as that afforded by the $\mathrm{Al}$ centre, which sometimes raises questions about the reliability of the $\mathrm{D}_{\mathrm{E}}$. However, by standardising and optimising the analytical protocol for the specific evaluation of Ti centres, it is nevertheless possible to get meaningful results, especially for the Ti-Li centre (Duval and Guilarte, 2015); though ESR measurements can take several hours and require optimum stability and careful control of the experimental conditions (Duval and Guilarte Moreno, 2012). Despite these improvements in Ti-centre measurements, the evaluation of the Ti-H centre remains complicated, as it can rarely be measured and the reliability of the corresponding results is doubtful in most cases (Duval et al., 2015a,b).

Consequently, the systematic measurement of both Al- and Ti-centres in a given sample should be seen as a necessary quality control check to ensure reliable ESR results.

\section{Cuesta de la Bajada site}

Cuesta de la Bajada site (Teruel, Spain) is located in the Alfambra river valley within the Teruel Depression. A total of 10 fluvial terraces have been identified in this area, named T10 to T1 from the present-day floodplain to the highest deposits. Cuesta de la Bajada is part of the T4 terrace $(+50-53 \mathrm{~m}$ above the current river level), whose thickness is about $55 \mathrm{~m}$ due to syn-sedimentary subsidence phenomena (Santonja et al., 2014 and references therein). The deposits are dominated by upward fining cycles of gravels and flood- plain deposits characteristic of a gravel-dominated braided river channel (Fig. 2).

The local stratigraphic sequence at the site is about $3 \mathrm{~m}$ thick and has been divided into five main units (Santonja et al., 2014 and references therein). At the bottom, layer $\mathrm{G}$ is dominated by sub-angular to sub-rounded pebbles (Fig. 2). The overlying layers, named CB-3, CB-2 and CB-1 from bottom to top, are dominated by clays, sands and coarser deposits whose relative proportion varies vertically. These three layers are topped by floodplain sediment (Unit P).

Hominin presence at Cuesta de la Bajada is documented by lithic artefacts (Santonja et al., 2014) and evidence of percussion and cut marks on bones (Domínguez-Rodrigo et al., 2015) found in layers CB1, CB2 and CB3. The homogeneity of the archaeological material makes it impossible to differentiate these three layers from a techno-typological perspective. The lithic assemblage may be attributed to the early Middle Palaeolithic technocomplex and comprises hammerstones, cores, flake tools and other products documenting a complete chaîne opératoire. The preserved lithic record therefore indicates that knapping was performed in situ (Santonja et al., 2014).

From a biostratigraphic perspective, the large mammal assemblage at Cuesta de la Bajada includes several taxa such as Equus caballus, Cervus elaphus, Stephanorhinus hemitoechus and Canis lupus (Santonja et al., 2014) that can be correlated to the Middle Pleistocene Faunal Unit (FU) 6 defined at the Atapuerca sites (Spain) (Rodríguez et al., 2011). The micromammal assemblage is also consistent with this correlation, and includes the rodent taxa Cricetulus (Allocricetus) bursae, Apodemus cf. sylvaticus, Microtus brecciensis (= Iberomys brecciensis, Cuenca-Bescós et al., 2014) and Arvicola aff. sapidus (Santonja et al., 2014). In terms of biochronology, the associated rodent assemblage may be included within the Middle Pleistocene Iberomys brecciensis biozone defined by Cuenca Bescos et al. (2010). At Atapuerca, FU6 covers TD8, TD10 and TD11 levels at Gran Dolina, GII and GIII at Galería, TE18 and TE19 at Sima del Elefante, and Sima de los Huesos (SH) (Rodríguez et al., 2011). Numerical ages available for these sites may help to roughly constrain the chronology of this faunal unit, providing thus a (very) approximated time range for Cuesta de la Bajada: combined US-ESR dating of fossil teeth suggest a chronology ranging from $610 \pm 65$ ka for TD8 (Falguères et al., 1999; Parés et al., 2013) to $230 \pm 9$ ka for TGIII, whereas thermoluminescence (TL) and infrared stimulated luminescence (IRSL) ages obtained by Berger et al. (2008) indicate an alternative chronology ranging from $820 \pm 140 \mathrm{ka}$ for TD 8 to $198 \pm 19 \mathrm{ka}$ for TD11.

So far, there is only a limited number of numerical ages available in the surroundings of Cuesta de la Bajada site. Santonja and Perez Gonzalez (2000) briefly mention one TL age of $138 \pm 10 \mathrm{ka}$ for a sample collected below the excavated layers. However, the absence of details the methodology employed precludes its use as a reference for assessing the chronology of the site. U-series dating of tufa deposits above an equivalent terrace in the Alfambra valley at Los Baños, a few km North from Cuesta de la Bajada, provided several chronological results: Arlegui et al. (2006) obtained two ages of $169 \pm 10 \mathrm{ka}$ and $116 \pm 4 \mathrm{ka}$, while Gutierrez et al. (2008) published results of $250+32 /-25 \mathrm{ka}$ and $213+33 /-26 \mathrm{ka}$. Since these tufa deposits cap the fluvial deposits of the terrace, the U-series ages might provide a minimum age estimate for Cuesta de la Bajada. However, the large scatter in the U-series ages, as well as the absence of details given by Gutierrez et al. (2008), in particular about the detrital ${ }^{232} \mathrm{Th}$ content, do not allow any clear and definitive conclusion to be made about methodological reliability.

A series of numerical ages has recently been published by Santonja et al. (2014) for Cuesta de la Bajada excavation area. While the ESR and OSL ages on quartz grains range between 250 and 

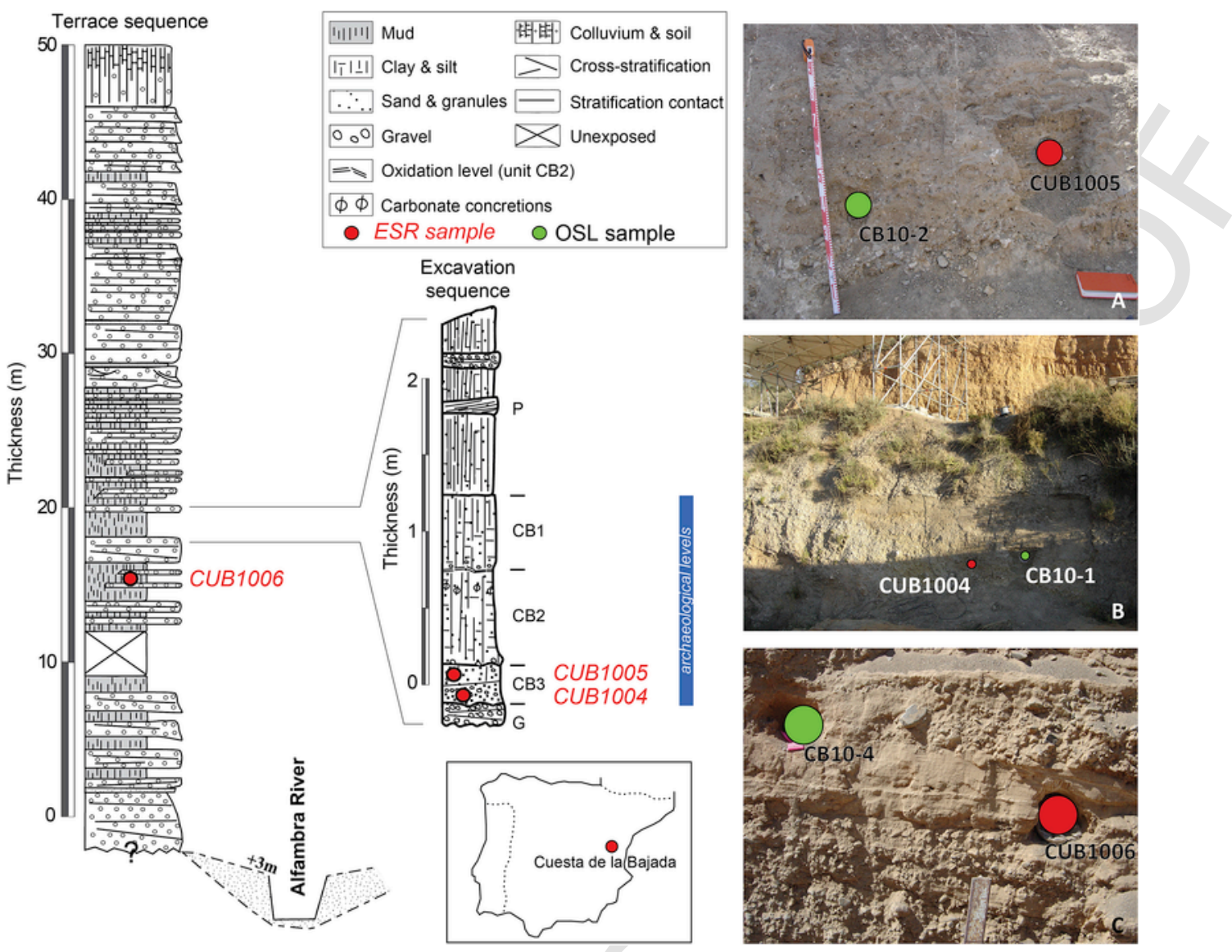

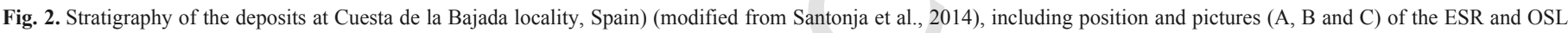
samples. Colours are available on the pdf version of the paper.

$350 \mathrm{ka}$ (full details are provided in the present work and companion paper by Arnold et al., 2016), amino acid racemization (AAR) analysis of five equid teeth from CB-3 provided an older chronology, with a mean age of $431 \pm 44 \mathrm{ka}$. Additionally, combined US-ESR dating of four fossil teeth collected from CB-3 provided very scattered results ranging from $215 \pm 15 \mathrm{ka}$ to $737 \pm 69 \mathrm{ka}$ (Bahain et al., 2015). The considerable amount of scatter in these US-ESR ages is likely attributable to the unexpectedly large variability in the observed $D_{E}$ values ( $55 \%$, corresponding to 1 standard deviation), and precludes the calculation of a meaningful mean age. In sum, the available chronology for Cuesta de la Bajada is highly scattered and the employed dating methodologies are usually not fully described. This underscores the significance of undertaking a detailed ESR study of the site.

\section{ESR sampling}

Three sediment samples were collected on site, by hammering a PVC tube into the outcrop in order to prevent any sunlight exposure. Sample CUB1005 were taken from layer CB-3 within the excavation area, while CUB1004 lies stratigraphically below CUB1005 by about $60 \mathrm{~cm}$. Sample CUB1006 was collected below the excavated layers, about $80 \mathrm{~cm}$ beneath sample CUB1004 (Fig. 2). Additional OSL samples were collected adjacent to the three ESR sample, each one being laterally distant by $<1 \mathrm{~m}$ (Fig. 2). Raw sediment samples were also collected for the evaluation of water content and additional laboratory dosimetry analyses.

\section{Methods}

The sediment samples were prepared in a dark room with dimmed red light according to the following protocol: the 100-200 $\mu \mathrm{m}$ size fraction was collected after wet sieving; $\mathrm{HCl}(18 \%$ and then $36 \%)$ was used to dissolve carbonates, and $\mathrm{H}_{2} \mathrm{O}_{2}(30 \%)$ was used to eliminate organic matter. Density separations were performed using sodium polytungstate (SPT) at $\mathrm{d}=2.72 \mathrm{~g} / \mathrm{cm}^{3}$ and $\mathrm{d}=2.62 \mathrm{~g} / \mathrm{cm}^{3}$, to remove heavy minerals and feldspars, respectively. The samples were then treated with HF (40\%) for 40 min to eliminate the remaining feldspars and to etch quartz grains. Finally, a neodymium magnet was passed over the sediment to remove any magnetic minerals, and a second round of (dry) sieving was carried out to isolate the $100-200 \mu \mathrm{m}$ size fraction.

Each prepared fraction of the natural samples was divided into 12 aliquots. Ten of these aliquots were irradiated using a ${ }^{60} \mathrm{Co}$ gamma source (Gammacell 220) with a dose rate of $12.81 \mathrm{~Gy} / \mathrm{min}$ at the following doses: 250, 400, 630, 1000, 1600, 2500, 4000, 6000, 8500 and 12,000 Gy. The non-bleachable residual ESR signals of the Aluminium centre were measured after exposing an aliquot of each natural sample in a SOL 500 (Dr Hönle) solar light simulator for $1065 \mathrm{~h}$.

ESR measurements were carried out at the Centro Nacional de Investigación sobre la Evolución Humana (CENIEH, Burgos) with an EMXmicro 6/1Bruker X-band ESR spectrometer coupled to a standard rectangular ER 4102ST cavity. To ensure constant experimental conditions over time, the temperature of the water circulating in the 
magnet is controlled and stabilized at $18{ }^{\circ} \mathrm{C}$ by a water-cooled Thermo Scientific NESLAB ThermoFlex 3500 chiller, and the temperature of the room was kept constant at $20{ }^{\circ} \mathrm{C}$ by an air conditioning unit. ESR measurements were performed at low temperature $(90 \pm 0.1 \mathrm{~K})$ using a ER4141VT Digital Temperature control system based on liquid nitrogen cooling. Further details about the setup and about its stability over time can be found in Duval and Guilarte Moreno (2012).

The ESR signal associated with the Al centre was measured as follows: $10 \mathrm{~mW}$ microwave power, 1024 points resolution, $20 \mathrm{mT}$ sweep width, $100 \mathrm{kHz}$ modulation frequency, $0.1 \mathrm{mT}$ modulation amplitude, $40 \mathrm{~ms}$ conversion time, $10 \mathrm{~ms}$ time constant and 1 scan. Each aliquot was measured 3 times after $\sim 120^{\circ}$ rotation in the cavity in order to consider angular dependence of the signal due to sample heterogeneity. The ESR measurements were further repeated 3 to 4 times over distinct days to check the reproducibility of the $\mathrm{D}_{\mathrm{E}}$ values. A mean ESR intensity was extracted for $\mathrm{D}_{\mathrm{E}}$ calculation. The ESR intensity of the Al signal was evaluated from peak-to-peak amplitude measurements between the top of the first peak and the bottom of the last peak, as indicated in Fig. 3.

The ESR signal associated with the Ti centres was measured as follows: $5 \mathrm{~mW}$ microwave power, 1024 points resolution, $20 \mathrm{mT}$ sweep width, $100 \mathrm{kHz}$ modulation frequency, $0.1 \mathrm{mT}$ modulation am- plitude, $60 \mathrm{~ms}$ conversion time, $10 \mathrm{~ms}$ time constant and from 2 to 15 scans to ensure a good $\mathrm{S} / \mathrm{N}$ ratio. Each sample was measured 4 times and a mean ESR intensity was extracted for $\mathrm{D}_{\mathrm{E}}$ calculation. The ESR intensity of the Ti signal was evaluated in various ways (options A to E; Fig. 3), as described in Duval and Guilarte (2015).

ESR intensities of $\mathrm{Al}$ and $\mathrm{Ti}$ centres were corrected by the corresponding receiver gain value, number of scans, aliquot mass and a temperature correction factor (Duval and Guilarte Moreno, 2012). The fitting procedures were carried out with Microcal OriginPro 8.5 using a Levenberg-Marquardt algorithm by chi-square minimisation, and data were weighted by the inverse of the squared ESR intensity $\left(1 / \mathrm{I}^{2}\right)$. For the Al centre, an exponential + linear $(\mathrm{EXP}+\mathrm{LIN})$ function was fitted through the experimental points, as it has been demonstrated that this function better describes the analytical data set compared to the classic single saturating exponential function (SSE) (Duval, 2012). $\mathrm{D}_{\mathrm{E}}$ values were obtained by extrapolating the EXP + LIN function to the residual ESR intensity. For the Ti centres, the SSE was used and results were compared to those derived from the Ti-2 function (fitting equations are provided in Supplementary information Table S1). The goodness-of-fit was assessed using the adjusted $r$-square $\left(r^{2}\right)$ value, which accounts for the degrees of freedom of the system (see the Origin 8 User Guide for further details). Some examples of dose response curves (DRCs) are shown in Fig. 4.

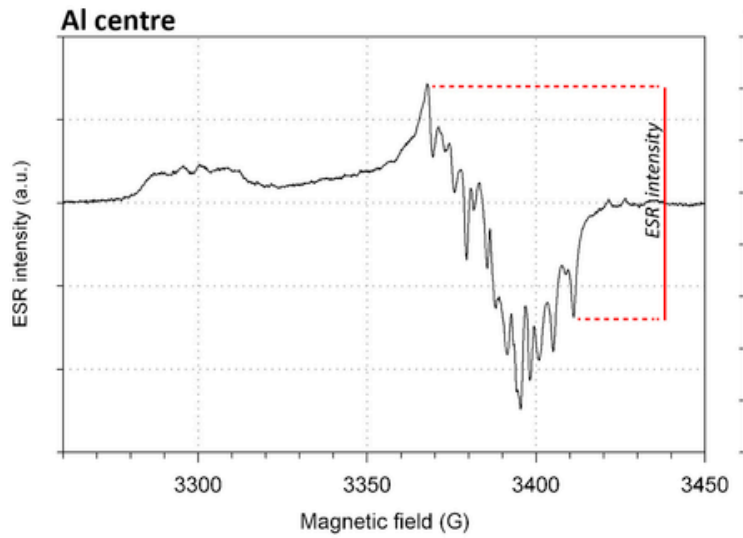

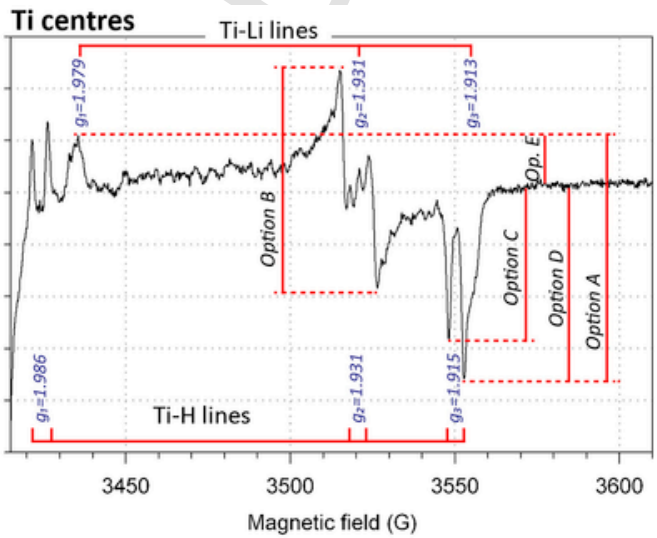

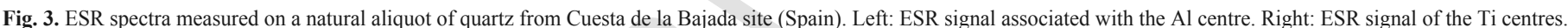

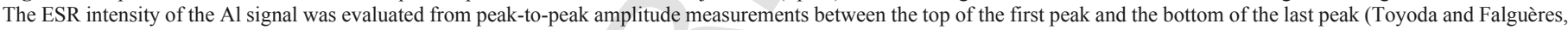

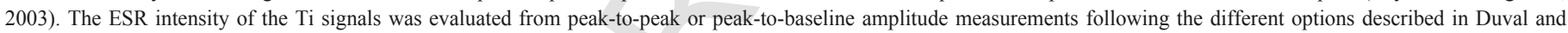
Guilarte (2015). Colours are available on the pdf version of the paper.
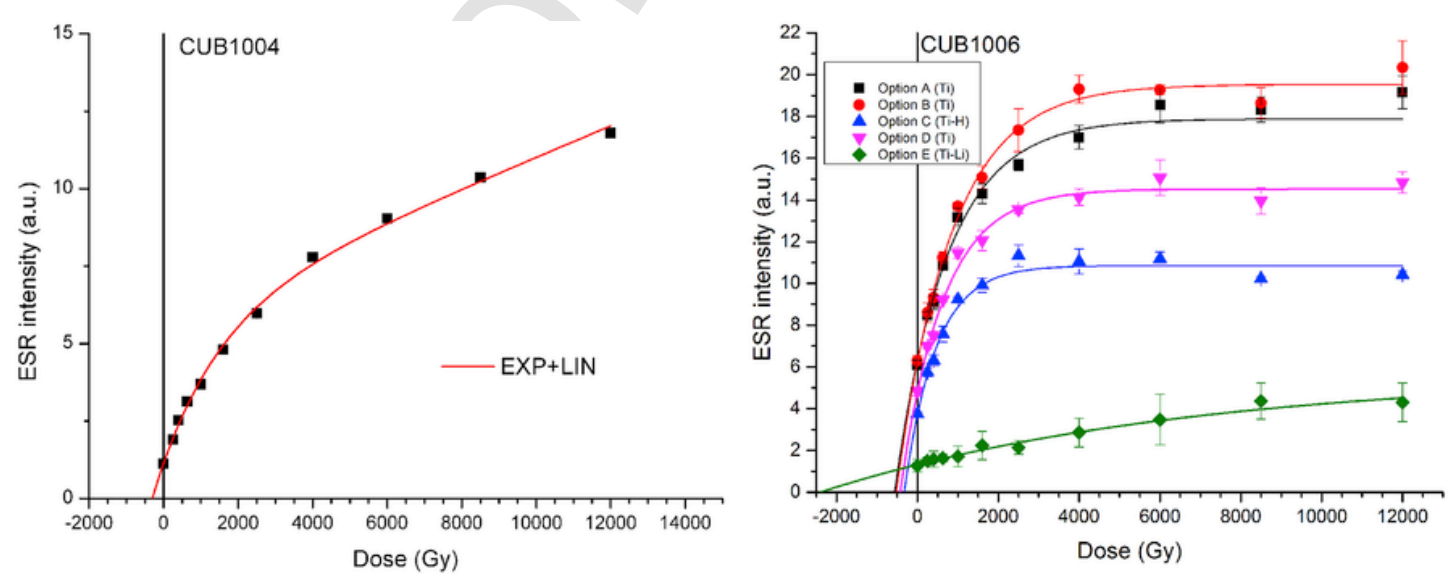

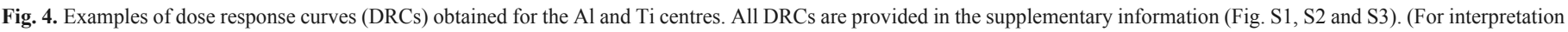
of the references to colour in this figure legend, the reader is referred to the web version of this article.) 
The total dose rate value was derived from a combination of in situ and laboratory measurements. The external gamma dose rate was measured in situ with a portable gamma spectrometer (Canberra Inspector 1000 coupled with a $1.5 \times 1.5$ inch $\mathrm{NaI}(\mathrm{Tl})$ probe) and calculated using the "threshold technique" (Duval and Arnold, 2013). Radioelement (U, Th, K) contents were determined by high resolution gamma spectrometry (HRGS) analysis performed with $\mathrm{HpGe}$ detectors on $\sim 120$ g of raw and dry sediments (collected from slightly deeper in the ESR sample holes). These data were used to derive external alpha and beta dose rate components using the dose rate conversion factors from Guérin et al. (2011). Beta dose rate was also derived from measurements with a Risø GM-25-5 low-level beta counter performed on small $(<5 \mathrm{~g})$ subsamples of bulk sediment taken directly from the ESR sampling position (Bøtter-Jensen and Mejdahl, 1988). Water content was assessed in the laboratory by drying the raw sediment at $50{ }^{\circ} \mathrm{C}$ during 3 weeks. Internal dose rate was assumed to be $50 \pm 30 \mathrm{uGy} / \mathrm{a}$, based on the work from Vandenberghe et al. (2008) and assuming an alpha efficiency $\mathrm{k}$ of $0.15 \pm 0.1$ (Yokoyama et al., 1985). Values were corrected for alpha and beta attenuation of spherical grains (Brennan et al., 1991; Brennan, 2003) and water attenuation using formulae from Grün (1994). The cosmic dose rate was calculated using formulae from Prescott and Hutton (1994), with depth, altitude and latitude corrections (Prescott and Hutton, 1988).

ESR age calculations were performed using a non-commercial SCILAB based software, with error assessed through Monte Carlo simulations. ESR age errors are given at $1 \sigma$.

\section{Results and discussion}

\subsection{Evaluating ESR data robustness and reliability}

\subsubsection{Al-centre}

The bleaching coefficient values vary within a narrow range (from 54.3 to $56.5 \%$ ), indicating very similar bleaching residuals for the various samples (Table 2). The ESR data collected for the three samples show good measurement repeatability, as the variability of the ESR intensities does not exceed 3\% (1 standard deviation). $\mathrm{D}_{\mathrm{E}}$ reproducibility (evaluated through the standard deviation of the mean De value) is very high for samples CUB1004 (7.2\%) and CUB1006 (4.0\%), while it is slightly lower for sample CUB1005 ( 12\%).

$\mathrm{D}_{\mathrm{E}}$ values were calculated by averaging the mean ESR intensities obtained over repeated measurements, and range from $722 \pm 64$ to $899 \pm 85$ Gy depending on the sample. With adjusted $r^{2}$ values systematically $>0.99$, the goodness-of-fit is considered to be highly suitable for all the samples and indicates the appropriateness of the

Table 2

ESR data derived from the measurements of $\mathrm{Al}$ centre. For a given sample: (i) measurement repeatability is assessed through the variability of the average ESR intensities obtained from each day of measurement ( 1 relative standard deviation); (ii) $\mathrm{D}_{\mathrm{E}}$ reproducibility is evaluated via the variability of the $D_{E}$ values obtained after each day of measurement (1 relative standard deviation). Fitting was performed with a EXP + LIN function with data weighted by $1 / \mathrm{I}^{2}$.

\begin{tabular}{|c|c|c|c|c|c|}
\hline Sample & Al centre & & & & \\
\hline & $\begin{array}{l}\text { Measurement } \\
\text { repeatability }(\%)\end{array}$ & $\begin{array}{l}D_{E} \\
\text { reproducibility } \\
(\%)\end{array}$ & $\begin{array}{l}\text { Bleaching } \\
\text { coef. }(\%)\end{array}$ & Adj. $\mathrm{r}^{2}$ & $\mathrm{D}_{\mathrm{E}}(\mathrm{Gy})$ \\
\hline CUB1004 & 2.4 & 7.2 & $56.5 \pm 0.3$ & 0.9967 & $789 \pm 75$ \\
\hline CUB1005 & 2.8 & 11.9 & $56.5 \pm 0.5$ & 0.9970 & $925 \pm 85$ \\
\hline CUB1006 & 2.0 & 4.0 & $54.3 \pm 0.4$ & 0.9971 & $722 \pm 64$ \\
\hline
\end{tabular}

EXP + LIN function for describing the increase of the signal with dose. All these proxies demonstrate the robustness of the ESR data based on the Al centre. DRCs are provided in supplementary information, Fig. S1.

\subsubsection{Ti-H centre}

The three samples from Cuesta de la Bajada are characterised by exceptionally high ESR intensities for the Ti-H signal (option C). These signals represent between $62 \%$ and $65 \%$ of the ESR intensity measured with option A. In contrast, this proportion did not exceed $37 \%$ in the six samples previously analysed by Duval and Guilarte (2015).

As expected, data robustness is not as good as that achieved for the Al centre: measurement repeatability ranges from 1.9\% (CUB1005) to $20.5 \%$ (CUB1006). The surprisingly high values obtained for samples CUB1004 and CUB1006 can simply be attributed to normal drift of the ESR spectrometer (Table 3). While the four measurements of sample CUB1005 were performed within eight days, the fourth ESR measurement of CUB1004 and CUB1006 were carried out almost one month after the first three ones. When excluding the values on Day \#4, the variability of the ESR intensities drops significantly to $<2 \%$. This does not affect $\mathrm{D}_{\mathrm{E}}$ reproducibility as these two samples show the lowest variability. In contrast, the corresponding $\mathrm{D}_{\mathrm{E}}$ variability for sample CUB1005 is $17 \%$, although it should be noted that repeated $D_{E}$ values are all within error.

The DRCs of the Ti-H signal are quite different from those of the Al centre (Fig. 4). Several papers have recently described the non-monotonic dose dependence of the Ti-centre signal at high doses (Woda and Wagner, 2007; Duval and Guilarte, 2015). Interestingly, the present data set does not clearly show such behavior. Instead, an almost saturated dose response is observed at high doses above $\sim 2500 \mathrm{~Gy}$ (Fig. 4). Two fitting functions (SSE and the so-called Ti-2; see equations in Table S1) were tested with option C: the SSE function provides $D_{E}$ values that are systematically lower than those derived from the Ti-2 function, but all $\mathrm{D}_{\mathrm{E}}$ values are consistent at 1 sigma for a given sample (see Table 3, Fig. 5 and Fig. S2). Furthermore, the SSE function shows a better goodness-of-fit for two of the three samples (CUB1004 and CUB1005).

A strong correlation between the maximum irradiation dose $\left(\mathrm{D}_{\max }\right)$ and the final $\mathrm{D}_{\mathrm{E}}$ value has been observed elsewhere for some materials when using the SSE function (e.g. Duval et al., 2009; Duval, 2012). To assess this potential bias, the fitting was performed with a SSE by successively removing the experimental points at high dose range (Fig. $5)$.

Table 3

ESR data derived from the measurements of the Ti-H centre. Fitting was performed with both SSE and Ti-2 functions with data weighted by $1 / \mathrm{I}^{2}$. For a given sample: (i) measurement repeatability is assessed through the variability of the average ESR intensities obtained from each day of measurement (1 relative standard deviation); (ii) $\mathrm{D}_{\mathrm{E}}$ reproducibility is evaluated via the variability of the $D_{E}$ values (using the SSE function) obtained after each day of measurement (1 relative standard deviation). Key: $\left({ }^{*}\right)$ without considering measurements on Day 4.

\begin{tabular}{lllllll}
\hline Sample & Ti-H & & & \\
\hline & Option C & & & & \\
\hline & $\begin{array}{l}\text { Measurement } \\
\text { repeatability } \\
(\%)\end{array}$ & $\begin{array}{l}\mathrm{D}_{\mathrm{E}} \\
\text { reproducibility } \\
(\%)\end{array}$ & Adj. $\mathrm{r}^{2}$ & $\begin{array}{l}\text { SSE D } \\
(\mathrm{Gy})\end{array}$ & Adj. $\mathrm{r}^{2}$ & $\begin{array}{l}\text { Ti-2 } \\
(\mathrm{Gy})\end{array}$ \\
\hline CUB1004 & $18.8\left[1.8^{*}\right]$ & 13.1 & 0.9800 & $665 \pm 93$ & 0.9797 & $720 \pm 1$ \\
CUB1005 & 1.9 & 17.0 & 0.9806 & $553 \pm 78$ & 0.9788 & $573 \pm 9$. \\
CUB1006 & $20.5\left[0.6^{*}\right]$ & 7.4 & 0.9880 & $329 \pm 38$ & 0.9936 & $363 \pm 3$. \\
\hline
\end{tabular}



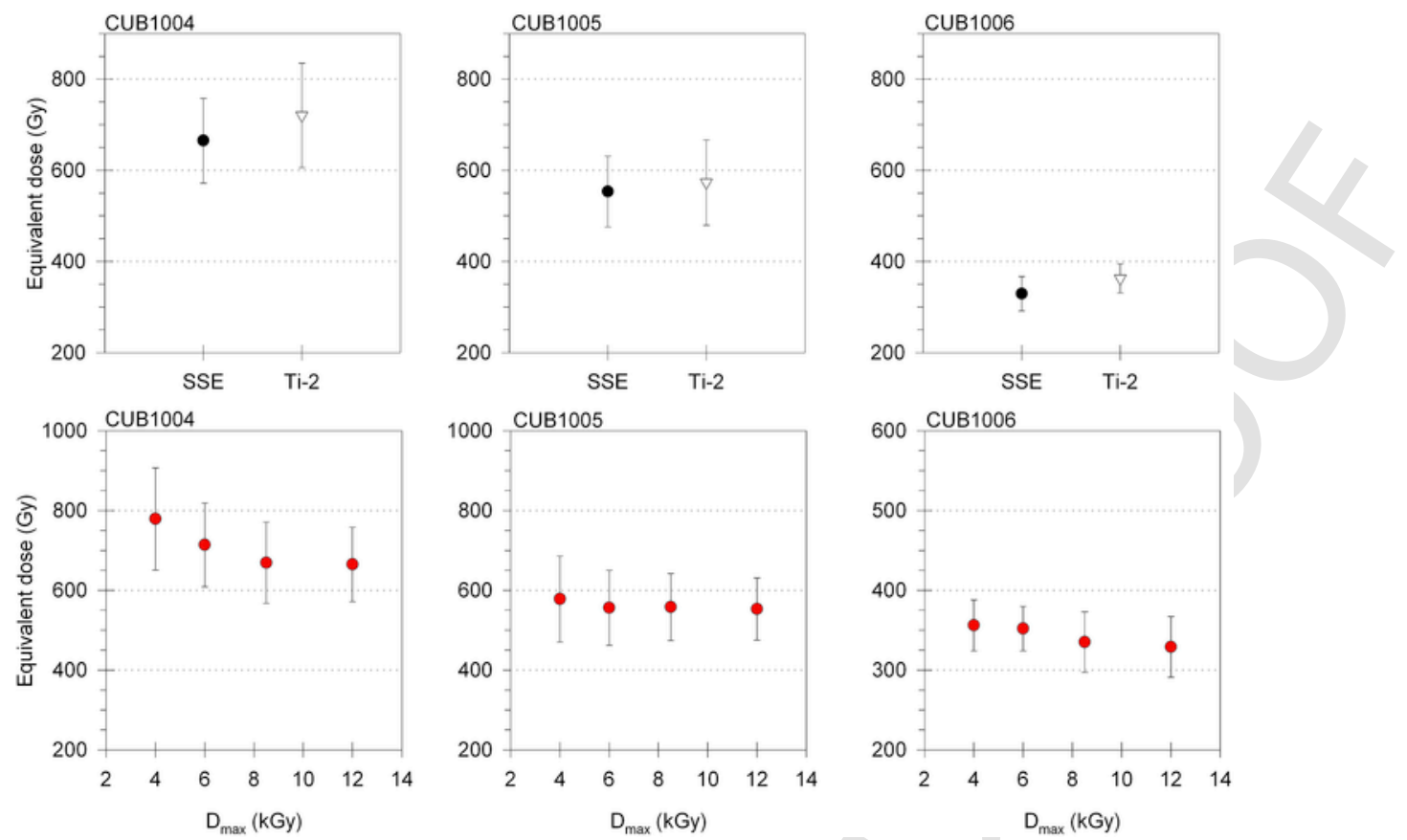

Fig. 5. Dose evaluation based on the Ti-H centre (option C). Top: Influence of the fitting function (SSE and Ti-2) on the $\mathrm{D}_{\mathrm{E}}$ result. Bottom: Impact of the $\mathrm{D}_{\text {max }}$ on the $\mathrm{D}_{\mathrm{E}}$ value.

The results of this comparison indicate there is very little influence of the $D_{\max }$ on the $D_{E}$ value. The $D_{E}$ values vary by $<5 \%$ (i.e. not beyond the error range) when changing the $\mathrm{D}_{\max }$ from $6 \mathrm{kGy}$ to $12 \mathrm{kGy}$ (Fig. 5). These results thus support the appropriateness of the SSE function for the present data set. Consequently, we have derived the final age estimates using this fitting function.

It should also be noted that the $\mathrm{Ti}-\mathrm{H}$ data robustness and reliability (e.g., goodness-of-fit) are consistently lower than those observed for the Al and Ti-Li centres. Nevertheless they remain much higher than any other samples previously analysed by the authors (see an overview in Duval and Guilarte, 2015). This is most likely attributable to the especially high concentrations of Ti-H centres in the Cuesta de la Bajada quartz grains. Consequently, there is a series of consistent proxies suggesting that dose estimates derived from the Ti-H centre in the present study may be considered as reliable from a methodological point of view.

\subsubsection{Ti-Li centre}

One of the main debates with the Ti-Li centre lies in the best option (integration range) to use for evaluating the ESR intensity. The favoured approach is usually to measure the peak-to-peak amplitude either between the peaks at $g=1.979$ and $g=1.915$ (e.g. Rink et al., 2007; named option A in Fig. 3), or between the peaks around $\mathrm{g}=1.931$ (e.g. Beerten et al., 2008; named option B here; Fig. 3), or the peak-to-baseline amplitude at $\mathrm{g}=1.915$ (e.g. Tissoux et al., 2007; named option D in the present work, Fig. 3). However, it should be emphasised that these options are most likely a mixture of contributions from $\mathrm{Ti}-\mathrm{Li}$ and $\mathrm{Ti}-\mathrm{H}$ centres, given that they both have absorption lines at very close g-values, i.e. at $\mathrm{g}=1.913$ and $\mathrm{g}=1.915$, respectively. In fact, the peak at $g=1.979$ (=option E, Fig. 3) is very likely the only way to measure the Ti-Li centre alone without any interference. In most cases, options $\mathrm{A}, \mathrm{D}$ and $\mathrm{E}$ yield consistent $\mathrm{D}_{\mathrm{E}}$ values (Duval and Guilarte, 2015), suggesting that the influence of the Ti-H centre is generally negligible, as its intensity is usually very weak in comparison with the Ti-Li. However, the samples from Cuesta de la Bajada show a distinct pattern. Although options A and $D$ yield consistent $D_{E}$ values at $2 \sigma$ (Table 4 ), there is an apparent sys- tematic, and significant, deviation in the results, with option A yielding $32 \%$ higher $\mathrm{D}_{\mathrm{E}}$ values on average (Fig. 5). Such a trend is very likely caused by the peak at $g=1.979$ : when isolated, this peak alone (option E) systematically provides $\mathrm{D}_{\mathrm{E}}$ values $>2000 \mathrm{~Gy}$, i.e. between 3.3 and 5.7 times higher than those from option D (Fig. 6 and Table 5 ). Although the reliability of the fitting results is counterbalanced by the poor goodness-of-fit values $\left(\mathrm{r}^{2}<0.97\right.$; Table 5), the significant, and systematic, $\mathrm{D}_{\mathrm{E}}$ overestimation produced by option $\mathrm{E}$ is consistent with the previous observations of Beerten et al. (2006). In addition, the vicinity of the Al signal, whose intensity is several times higher than that of the Ti centres, may also affect option E, and thus to some extent the resulting dose evaluation. Consequently, for the all the above mentioned reasons, the reliability of the $\mathrm{D}_{\mathrm{E}}$ values derived from both options $\mathrm{A}$ and $\mathrm{E}$ can thus be reasonably questioned, at least for the present dataset.

As previously mentioned, options B and D both represent a mixture of the Ti-Li and $\mathrm{Ti}-\mathrm{H}$ centres. Because the relative contributions of each centre in those options is unknown, the term Ti-Li-H centres (option D or B) will be used from now onwards. While Ti-centre option $\mathrm{D}$ shows measurement repeatability similar to that of the $\mathrm{Ti}-\mathrm{H}$ centre, the $\mathrm{D}_{\mathrm{E}}$ reproducibility appears to be, in contrast, significantly better on average $(<6 \%$, Table 4$)$. The DRCs of Ti-centre option D show an apparent saturation from $\sim 4 \mathrm{kGy}$ (Fig. S3). As with the Ti-H signal, both the SSE and Ti-2 fitting functions were used to assess $\mathrm{D}_{\mathrm{E}}$ dependency of Ti option $\mathrm{D}$ : the $\mathrm{D}_{\mathrm{E}}$ results are consistent, with relative differences of $<3 \%$, while the goodness-of-fit is slightly better when using the SSE function (Table 4). To assess the impact of the $D_{\max }$, the SSE fitting was repeatedly performed after successively removing data points in the high dose range (Fig. 6). The resultant $D_{E}$ results are all consistent for a given sample, irrespective of the chosen $\mathrm{D}_{\max }: \mathrm{D}_{\mathrm{E}}$ values change by $<2.8 \%$ when varying the $\mathrm{D}_{\max }$ from $6 \mathrm{kGy}$ to $12 \mathrm{kGy}$ (Fig. 6), confirming the appropriateness of the SSE function for this data set. The adjusted $\mathrm{r}^{2}$ values obtained with Ti-Li-H (option D) centres range from 0.987 to 0.992 (Table 4). These goodness-of-fit results lie between those obtained for the $\mathrm{Al}$ centre and the Ti-H centre. 
Table 4

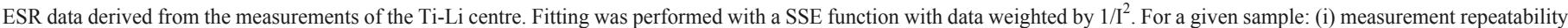

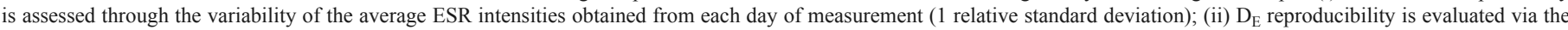
variability of the $D_{E}$ values obtained after each day of measurement (1 relative standard deviation). Key: $(*)$ without considering measurements on Day 4.

\begin{tabular}{|c|c|c|c|c|c|c|c|c|c|c|c|c|c|}
\hline Option & \multicolumn{2}{|l|}{ A } & \multicolumn{2}{|l|}{ B } & \multicolumn{6}{|l|}{$\mathrm{D}$} & $\mathrm{E}$ & \multicolumn{2}{|l|}{$\mathrm{F}$} \\
\hline Centre & \multicolumn{2}{|c|}{$\begin{array}{l}\text { Mixture of Ti-Li and } \\
\text { Ti-H }\end{array}$} & \multicolumn{2}{|c|}{$\begin{array}{l}\text { Mixture of Ti-Li and } \\
\text { Ti-H }\end{array}$} & \multicolumn{6}{|c|}{ Mixture of Ti-Li and $\mathrm{Ti}-\mathrm{H}$} & Ti-Li & \multicolumn{2}{|c|}{$\begin{array}{l}\text { Mixture of Ti-I } \\
\text { H (sum of optic } \\
\text { E ESR intensiti }\end{array}$} \\
\hline \multirow[t]{2}{*}{ Sample } & \multicolumn{2}{|c|}{ SSE function } & \multicolumn{2}{|c|}{ SSE function } & \multicolumn{4}{|l|}{ SSE function } & \multicolumn{2}{|c|}{$\mathrm{Ti}-2$ function } & SSE function & \multicolumn{2}{|c|}{ SSE function } \\
\hline & Adj. $r^{2}$ & $\mathrm{D}_{\mathrm{E}}(\mathrm{Gy})$ & Adj. $r^{2}$ & $\mathrm{D}_{\mathrm{E}}(\mathrm{Gy})$ & $\begin{array}{l}\text { Measurement } \\
\text { repeatability } \\
(\%)\end{array}$ & $\begin{array}{l}\mathrm{D}_{\mathrm{E}} \\
\text { reproducibility } \\
(\%)\end{array}$ & Adj. $r^{2}$ & $\mathrm{D}_{\mathrm{E}}(\mathrm{Gy})$ & Adj. $r^{2}$ & $\mathrm{D}_{\mathrm{E}}(\mathrm{Gy})$ & $\mathrm{D}_{\mathrm{E}}(\mathrm{Gy})$ & Adj. $r^{2}$ & $\mathrm{D}_{\mathrm{E}}(\mathrm{C}$ \\
\hline CUB1004 & 0.9926 & $1063 \pm 91$ & 0.9859 & $1011 \pm 119$ & $\begin{array}{l}19.2 \% \\
{[0.7 \% *]}\end{array}$ & $4.3 \%$ & 0.9921 & $795 \pm 70$ & 0.9913 & $820 \pm 92$ & $0.9612 \quad 4396 \pm 1089$ & 0.9831 & $984 \pm$ \\
\hline CUB1005 & 0.9896 & $962 \pm 98$ & 0.9797 & $923 \pm 135$ & $1.7 \%$ & $5.4 \%$ & 0.9872 & $733 \pm 84$ & 0.9854 & $733 \pm 90$ & $0.9517 \quad 2436 \pm 580$ & 0.9077 & $610 \beth$ \\
\hline CUB1006 & 0.9912 & $561 \pm 55$ & 0.9940 & $529 \pm 43$ & $\begin{array}{l}19.9 \% \\
{[0.7 \% *]}\end{array}$ & $1.6 \%$ & 0.9913 & $426 \pm 42$ & 0.9901 & $426 \pm 45$ & $2412 \pm 473$ & 0.9976 & $467 \pm$ \\
\hline
\end{tabular}
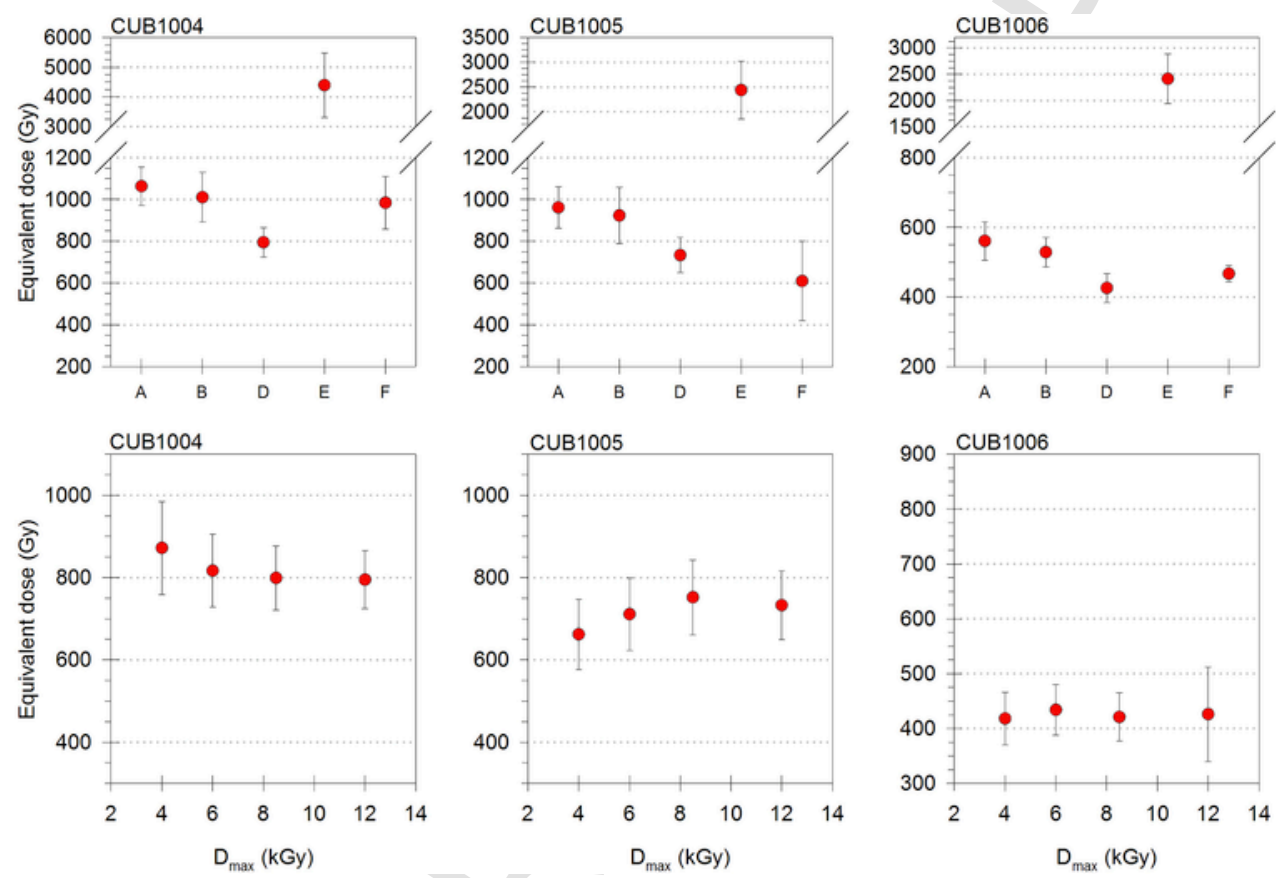

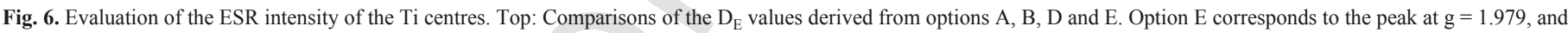

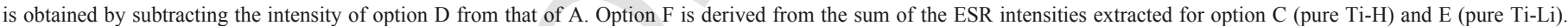
Bottom: Impact of $\mathrm{D}_{\max }$ on the final $\mathrm{D}_{\mathrm{E}}$ value (option $\mathrm{D}$ ) derived from the SSE function.

Table 5

Radionuclide activities measured by High Resolution Gamma Spectrometry (HRGS) for the 3 samples from Cuesta de la Bajada site.

\begin{tabular}{lllll}
\hline & $\mathrm{U}-238(\mathrm{~Bq} / \mathrm{kg})$ & $\mathrm{Rn}-222(\mathrm{~Bq} / \mathrm{kg})$ & $\mathrm{Th}-232(\mathrm{~Bq} / \mathrm{kg})$ & $\mathrm{K}(\%)$ \\
\hline CUB1004 & $22.7 \pm 2.70$ & $21.7 \pm 1.59$ & $18.7 \pm 0.53$ & $0.82 \pm 0.03$ \\
CUB1005 & $33.3 \pm 3.05$ & $36.8 \pm 3.02$ & $28.6 \pm 1.69$ & $1.29 \pm 0.04$ \\
CUB1006 & $12.6 \pm 1.56$ & $11.2 \pm 0.77$ & $11.3 \pm 0.78$ & $0.57 \pm 0.02$ \\
\hline
\end{tabular}

$D_{E}$ values derived using option $B$ are systematically higher than those obtained with option $\mathrm{D}$, but all results are in agreement within the $1 \sigma$ error ranges (Fig. 6). Overall, option B shows a lower goodness-of-fit for two of the three samples and, as a consequence, higher $\mathrm{D}_{\mathrm{E}}$ errors. These observations are consistent with those made by Duval and Guilarte (2015) and suggest that option D should be preferred to option B for dose evaluations.
Finally, the potential of another option was also explored for comparison: option $\mathrm{F}$ was obtained by summing ESR intensities of options $\mathrm{C}$ (pure Ti-H) and $\mathrm{E}$ (pure Ti-Li) in order to get to get a resulting intensity that may correspond to a total Ti concentration. $\mathrm{D}_{\mathrm{E}}$ results are somewhat consistent with option $\mathrm{D}$, but goodness-of-fit is lower for 2/ 3 samples. The third sample (CUB1006) for which $\mathrm{r}^{2}>0.99$ shows a $\mathrm{D}_{\mathrm{E}}$ value that is very close to that of option $\mathrm{D}$. This might indirectly indicate that relative contributions of Ti-Li and Ti-H centres in option $\mathrm{D}$ are similar to those of option F, but more conclusive data are required for the moment to confirm this hypothesis.

To summarise, a series of factors indicate the robustness of the Ti-centre ESR data derived using option D (i.e., good measurement repeatability and $D_{E}$ reproducibility), as well as the reliability of the dose estimates (goodness-of-fit, appropriateness of the SSE function). 


\subsection{Comparison of the $D_{E}$ values obtained from the different centres}

As meaningful ESR data can rarely be extracted from the Ti-H centre, the present work is one of the few studies in which the $\mathrm{Ti}$ and $\mathrm{Al}$ centres can be directly compared for a given sample (Fig. 7). The Ti-H centre (=option $\mathrm{C}$ ) provides the lowest $\mathrm{D}_{\mathrm{E}}$ values of the data set: they are $20 \%-57 \%$ lower than those calculated for the $\mathrm{Al}$ centre and between $16 \%$ and $25 \%$ lower than those derived from Ti-Li-H (option D) centre. In comparison, option $\mathrm{E}$ (pure $\mathrm{Ti}-\mathrm{Li}$ ) provides unreasonably high $\mathrm{D}_{\mathrm{E}}$ values ( $>2000 \mathrm{~Gy}$ ). This pattern is similar to that described by Beerten et al. (2008) and Tissoux et al. (2008).

Option C (Ti-H centre), option D (Ti-Li centre) and the Al centre all yield consistent $\mathrm{D}_{\mathrm{E}}$ values for sample CUB1004 (although the option $\mathrm{C}$ systematically provides the lowest $\mathrm{D}_{\mathrm{E}}$ values), suggesting possible adequate resetting of the bleachable Al signal prior to sediment deposition (according to the assumptions of the MC approach). In contrast, the other two samples exhibit Ti option $\mathrm{D}_{\mathrm{E}}$ values that are significantly lower than their Al equivalents; differing by 19 and $41 \%$ for samples CUB1005 and CUB1006, respectively.

\subsection{Dose rate evaluation}

HRGS analysis of $\sim 120 \mathrm{~g}$ of dry sediment collected in the same position as the ESR samples shows no significant disequilibrium in the ${ }^{238} \mathrm{U}$ decay chain; ${ }^{222} \mathrm{Rn}$ and ${ }^{238} \mathrm{U}$ activities being systematically within error (Table 5).

Sediment was analysed in situ as well as in the laboratory by HRGS and total beta counting in order to check the consistency of the various approaches used for evaluation of the different dose rate components (Table 6). Gamma dose rates derived from in situ measurements and HRGS analysis are in agreement for samples CUB1004 and CUB1005. In contrast, sample CUB1006 shows a significant rel- ative difference of $\sim 25 \%$ between the two methods. This is very likely due to spatial heterogeneity in the sedimentary environment of this sample. Unlike samples CUB1004 and CUB1005, which were collected from apparently homogenous deposits, CUB1006 was collected from a $\sim 10 \mathrm{~cm}$ thick layer of fine to medium sandy deposits that were surrounded by coarser deposits (Fig. 2). Beta dose rates calculated from dry sediment show the same pattern: results derived from total beta counting and HRGS are consistent for samples CUB1004 and CUB1005, whereas a difference of $\sim 17 \%$ is apparent for sample CUB1006. Again, this difference is very likely due to lateral variations of the sediment matrix and the limited extent of the sandy layer, since the raw sediment for HRGS was collected slightly deeper into the ESR sample hole. Given these observations, we consider the total beta counting results obtained directly from the ESR sample itself to provide the most accurate estimation of the true beta dose rate for CUB1006.

\subsection{ESR age estimates}

ESR age estimates were calculated using: (i) the final $D_{E}$ values obtained by pooling all the ESR intensities from each repeated measurement (see Duval, 2012); (ii) water content values corresponding to $60 \%$ of the saturated water content estimated in the laboratory; (iii) beta dose rate derived from total beta counting for sample CUB1006 and from HRGS analyses for the other two samples. The final ages obtained for the three samples are shown in Fig. 8 and Table 7.

It should be noted that the aforementioned parameters used for the age calculations differ slightly from those published in Santonja et al. (2014). These updated calculations have resulted in a marginally younger age (by 7\%) for sample CUB1005. However, this difference is not significant, as both results remain consistent within the $1 \sigma$-error range.
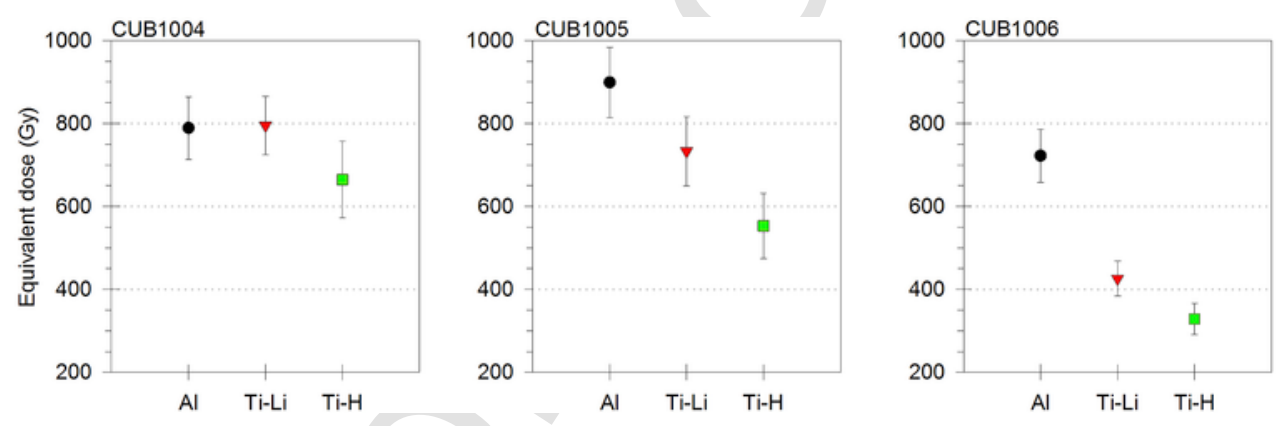

Fig. 7. Overview of the $\mathrm{D}_{\mathrm{E}}$ values derived from the Ti-H, Ti-Li and $\mathrm{Al}$ centres for the three samples.

Table 6

Comparison of gamma and beta dose rates derived from different analytical techniques.

\begin{tabular}{|c|c|c|c|c|c|c|c|}
\hline \multirow[t]{2}{*}{ Sample } & \multirow[t]{2}{*}{ Measured water content $(\%)$} & \multicolumn{3}{|c|}{ Gamma dose rate $(\mu \mathrm{Gy} / \mathrm{a})$} & \multicolumn{3}{|c|}{ Beta dose rate $(\mu \mathrm{Gy} / \mathrm{a})$} \\
\hline & & In situ & Laboratory & Laboratory & Lab. & Lab. & Lab. \\
\hline & & Threshold & HRGS Pre- $\mathrm{Rn}^{\mathrm{a}}$ & HRGS full series ${ }^{b}$ & Beta counting $^{c}$ & HRGS Pre- $R n^{c}$ & HRGS full series ${ }^{\mathrm{c}}$ \\
\hline CUB1004 & $7.1 \%$ & $523 \pm 29$ & $564 \pm 76$ & $572 \pm 72$ & $1055 \pm 43$ & $1031 \pm 151$ & $1038 \pm 132$ \\
\hline CUB1005 & $11.5 \%$ & $844 \pm 47$ & $850 \pm 104$ & $825 \pm 94$ & $1577 \pm 63$ & $1627 \pm 229$ & $1604 \pm 183$ \\
\hline CUB1006 & $2.7 \%$ & $444 \pm 25$ & $330 \pm 47$ & $341 \pm 50$ & $796 \pm 33$ & $662 \pm 107$ & $671 \pm 98$ \\
\hline
\end{tabular}

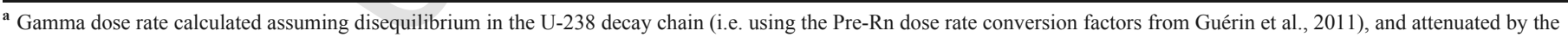
measured water content for a given sample.

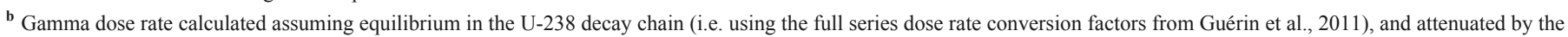
measured water content for a given sample.

${ }^{\mathbf{c}}$ Non-attenuated beta dose rates calculated for dry sediment. 


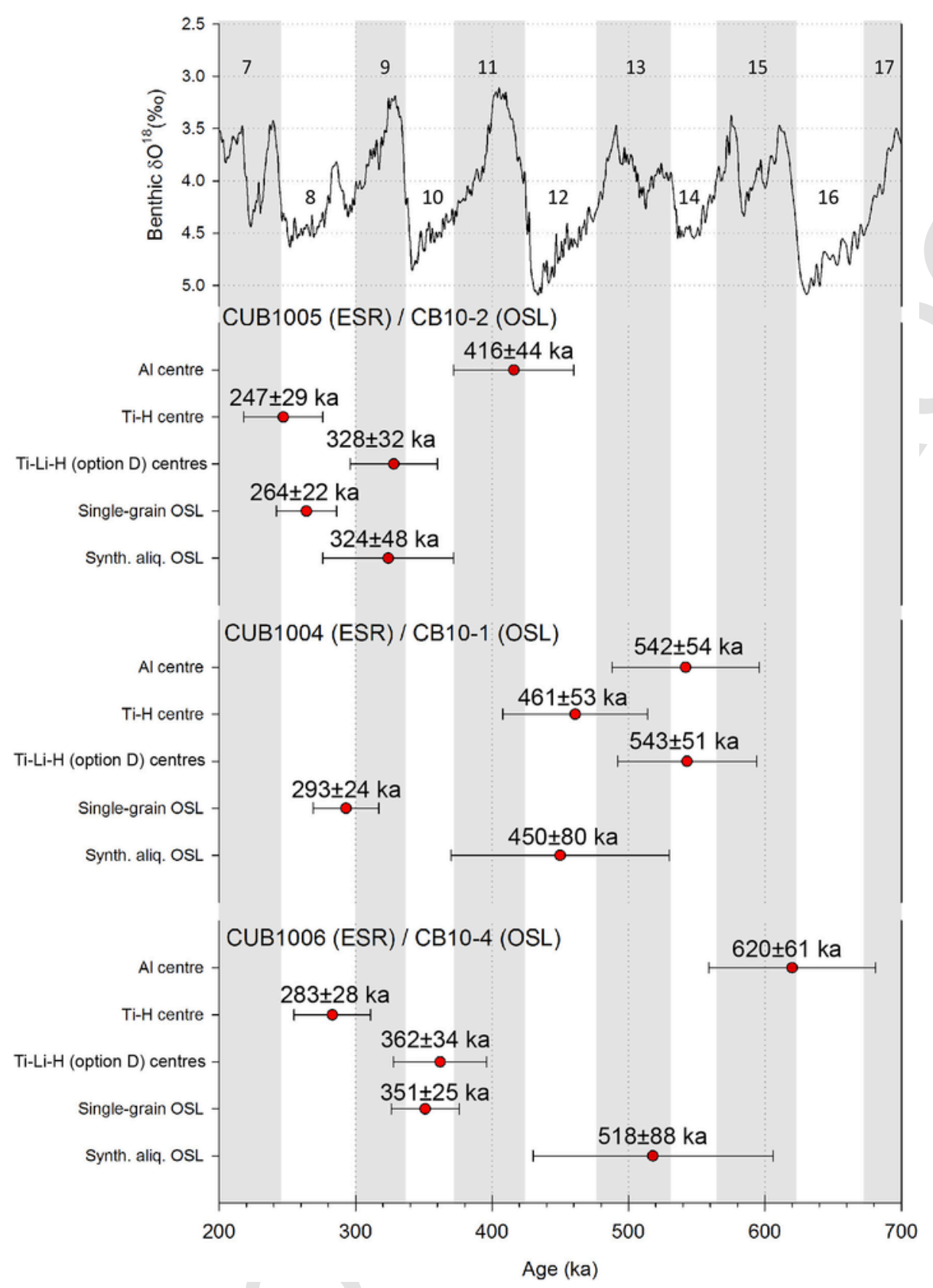

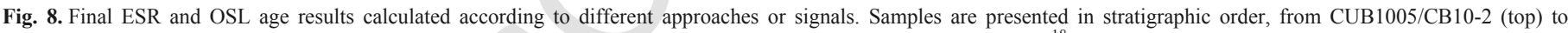
CUB1006/CB10-4 (bottom). Ages are correlated with the Marine Isotopic Stages (MIS) derived from the LR04 benthic d ${ }^{18} \mathrm{O}$ stack (Lisiecki and Raymo, 2005).

The dose rate calculations highlight the large variability of the radioactive environment within the Cuesta de la Bajada sequence. The gamma and beta dose rate values of individual samples vary by a factor of two. Three sets of ESR age estimates have been obtained using different selected ESR signals (Al, Ti-H and Ti-option D). We have opted not to calculate an age for Ti-Li (option E) given the unreliable fitting results that were achieved (i.e., poor goodness-of-fit, $\mathrm{D}_{\mathrm{E}}$ values $>2000$ Gy).

The results show the same pattern that has been previously observed for the $\mathrm{MC}$ approach: for a given sample the Al centre systematically provides the oldest age, whereas the Ti-H signal yields the youngest results. The Ti-option $\mathrm{D}$ signal provide age estimates that are on average $26 \%$ higher than those derived from the $\mathrm{Ti}-\mathrm{H}$ signal (with $1 / 3$ samples consistent at $1 \sigma$ and $2 / 3$ consistent at $2 \sigma$ ), while the Ti-option $\mathrm{D}$ ages are on average $21 \%$ lower than their $\mathrm{Al}$ equivalents (with $1 / 3$ samples consistent at $1 \sigma$ and $2 / 3$ consistent at $2 \sigma$ ).

The Al centre ESR age estimates are in stratigraphic order and range from $416 \pm 44 \mathrm{ka}(\mathrm{CUB} 1005)$ at the top to $620 \pm 61 \mathrm{ka}$ (CUB1006) at the bottom of the local sequence. Following the principles of the MC approach, these estimates should be considered as maximum possible ages given the slow optical bleaching kinetics of the Al centre. For one sample (CUB1004), the three ESR age estimates are all consistent at 1 sigma, suggesting that the Al signal has been fully bleached to its residual level prior to deposition. This is sometimes seen as important additional evidence of age accuracy (e.g. Rink et al., 2007), but the Ti results of the surrounding samples 
Table 7

ESR age estimates obtained for samples CUB1004, CUB1005 and CUB1006.Key: (*) final $D_{E}$ values were calculated by pooling all the ESR intensities derived from the repeated measurements, which has virtually no impact on the $D_{E}$ value but result in an improved associated error (Duval, 2012). (**) Ti-Li-H and Ti-H ages estimates obtained for sample CUB1005 slightly differ, (but remain within error) from those published by Santonja et al. (2014).

\begin{tabular}{llll}
\hline Sample & CUB1004 & CUB1005 & CUB1006 \\
\hline Internal dose rate (microGy/a) & $50 \pm 30$ & $50 \pm 30$ & $50 \pm 30$ \\
Alpha dose rate (microGy/a) & $30 \pm 27$ & $47 \pm 40$ & $22 \pm 19$ \\
Beta dose rate (microGy/a) & $836 \pm 64$ & $1267 \pm 98$ & $648 \pm 56$ \\
Gamma dose rate (microGy/a) & $514 \pm 42$ & $843 \pm 71$ & $425 \pm 35$ \\
Cosmic dose rate (microGy/a) & $24 \pm 4$ & $24 \pm 5$ & $24 \pm 5$ \\
Total dose rate (microGy/a) & $1456 \pm 108$ & $2231 \pm 167$ & $1169 \pm 87$ \\
$\mathrm{D}_{\mathrm{E}}(\mathrm{Gy})$ Al centre $(*)$ & $789 \pm 53$ & $929 \pm 68$ & $725 \pm 46$ \\
$\mathrm{D}_{\mathrm{E}}(\mathrm{Gy})$ Ti-H centre $(*)$ & $671 \pm 58$ & $551 \pm 49$ & $331 \pm 22$ \\
$\mathrm{D}_{\mathrm{E}}(\mathrm{Gy})$ Ti-Li-H centres Option D $\left(^{*}\right)$ & $792 \pm 45$ & $732 \pm 46$ & $423 \pm 25$ \\
Age (ka) Al centre & $542 \pm 54$ & $416 \pm 44$ & $620 \pm 61$ \\
Age (ka) Ti-H centre & $461 \pm 53$ & $247 \pm 29(* *)$ & $283 \pm 28$ \\
Age (ka) Ti-Li-H centres (option D) & $543 \pm 51$ & $328 \pm 32(* *)$ & $362 \pm 34$ \\
\hline
\end{tabular}

provide a different perspective. For samples CUB1005 and CUB1006, each of the Ti-centre options are in good agreement at 1 sigma, and they are consistent with the stratigraphy: they provide a chronology between $247 \pm 29$ and $283 \pm 28 \mathrm{ka}$ based on option C (Ti-H centre) and between $328 \pm 32$ and $362 \pm 34$ ka with option D (Ti-Li-H centres). In contrast, sample CUB1004 yields significantly older Ti-centre ages of between $461 \pm 53 \mathrm{ka}$ and $543 \pm 51 \mathrm{ka}$, depending on the option selected. The Ti-centre ages of CUB1004 therefore appear significantly overestimated in comparison with the results from the other two samples: the Ti ages of this sample are higher by $>200 \mathrm{ka}$ in comparison to those obtained for CUB1005, which was collected from the same layer (CB3) and is located above CUB1004 by only $\sim 60 \mathrm{~cm}$.

Several possible explanations may be envisaged to account for the apparent age overestimation of CUB1004. For example, incomplete bleaching of both the $\mathrm{Al}$ and $\mathrm{Ti}$ centres remains a possibility, and could have resulted in an overestimation of the calculated $\mathrm{D}_{\mathrm{E}}$ values for CUB1004. However, we do not have any direct evidence to confirm this hypothesis and this problem does not appear to have similarly affected sample CUB1005 from the same layer. Additionally, it should be mentioned here that the ESR spectra of the bleached aliquots of each sample showed that all the Ti signals were fully reset, precluding thus the possibility of a residual, non-bleachable component, that would induce a $\mathrm{D}_{\mathrm{E}}$ overestimation for sample CUB1004. Another explanation might be an underestimation of the dose rate, since the total dose rate calculated for CUB1004 is about 33\% lower than that obtained for CUB1005. However, this seems unlikely because laboratory and in situ measurements showed consistent values (Table 6). That said, we cannot rule out the possibility of recent radionuclide mobilization within the sediment matrix, or other time-dependent changes in dose rate that cannot be directly detected in the present-day environment. Consequently, the underlying phenomenon leading to the age overestimation of CUB1004 is not definitively known, and will require further investigation.

\subsection{Comparison with OSL ages on quartz grains}

ESR and OSL dating studies were performed independently, i.e. using the specific methodology and instrumentation for each technique. Full details about the companion single-grain OSL dating are provided in Arnold et al. (2016). The quartz samples from this site exhibit exceptional OSL dose saturation properties and contain significant populations of individual 'supergrains' with bright OSL signals and very high characteristic saturation dose $\left(\mathrm{D}_{0}\right)$ limits of 200 to $>600 \mathrm{~Gy}$. These favourable properties have permitted the establishment of single-grain OSL ages that exceed the traditional upper age limits of quartz OSL dating at Cuesta de la Bajada. The calculated single-grain SAR OSL age estimates range from $264 \pm 22 \mathrm{ka}$ to $351 \pm 25 \mathrm{ka}$ (Fig. 8). These ages are systematically lower than those obtained using the Al centre, but they are in good agreement with those obtained using the $\mathrm{Ti}$ centres for samples CUB1005 and CUB1006. The single grain OSL age obtained for CUB1005 is similar to the Ti-H ESR age for this sample $(247 \pm 29$ vs $264 \pm 22 \mathrm{ka})$, while the single-grain OSL age of sample CUB1006 is closer to the corresponding ESR age obtained using Ti-option D (351 \pm 25 vs $362 \pm 34 \mathrm{ka}$ ). In contrast, the ESR ages of sample CUB1004 are significantly older than the associated single-grain OSL age.

In terms of dating precision, the $\mathrm{Al}$ ages have average $1 \sigma$ uncertainties of $10.3 \%$ for the three samples. The precision afforded by the Ti centres is slightly lower at $15.3 \%$ and $12.7 \%$ for the Ti-H and Ti-Li-H (option D) centres, respectively. These differences in precision primarily originate from the $\mathrm{D}_{\mathrm{E}}$ determination procedure, and relate particularly to the repeatability of the ESR measurements for each centre. In comparison, the single grain OSL ages have a mean uncertainty of $7.9 \%$, while the simulated multi-grain aliquot OSL ages of Arnold et al. (2016) have a similar precision to the ESR ages $(\sim 16.6 \%$ on average).

Differences in the specific methodologies employed in the OSL and ESR studies may potentially introduce bias in our dating comparison at Cuesta de la Bajada. Several sources of uncertainty can be identified, but their real impact on the final ages may be difficult to quantify; particularly differences in the chosen grain size range $(100-200 \mu \mathrm{m}$ in ESR vs $212-250 \mu \mathrm{m}$ in OSL), or differences in the approach employed for $\mathrm{D}_{\mathrm{E}}$ reconstruction (single aliquot regenerative dose method in OSL vs multiple aliquot additive dose method in ESR). Differences in the number of grains analysed between the two studies represents another important consideration: single grain analyses were performed on the OSL samples, while multiple grain aliquots were used in the ESR study. Furthermore, the ESR measurements were performed on aliquot masses of $<300 \mathrm{mg}$, which may approximately correspond to between 27,000 and 216,000 quartz grains per tube. The impact of grain averaging may be directly assessed in single-grain OSL dating studies by creating simulated multiple grain aliquots (e.g. Arnold et al., 2012). This is achieved by deriving a summed $D_{e}$ value from all the grains contained on a single grain disc, including grains that were considered unreliable for dating and were previously rejected during the single grains analysis (e.g. Arnold et al., 2013) (with the exception of grain showing signals related to feldspar contamination or inclusions). This approach was employed in the companion study of Arnold et al. (2016), resulting in the creation of synthetic multi-grain aliquots containing about 95 grains each. The multi grain OSL ages obtained from these simulations are systematically older than the corresponding single grain ages of each sample by $23 \%-54 \%$. Interestingly, comparison of the synthetic aliquot results for OSL samples CB10-1 (= ESR sample CUB1004) and CB10-2 (= ESR sample CUB1005), which were taken from the same layer, reveal different degrees of multi-grain averaging effects (Fig. 8). For the former, the multi-grain averaging effects appear more significant, and the resultant synthetic aliquot OSL ages are surprisingly consistent with the $\mathrm{Ti}$ and $\mathrm{Al}$ ages (albeit with a large associated uncertainty range). This observation opens up the possibility that multi-grain averaging effects might also be affecting the ESR ages of samples CUB1004 and CUB1005 to different extents. This may offer another possible explanation for the ESR age overestimation of the latter sample. However, the potential parallels between multi-grain OSL averaging effects and ESR average effects do not 
seem applicable to sample CUB1006, for which the multi-grain OSL age is significantly higher than the Ti ESR ages.

Although it would be tempting to explain the ESR age overestimation of sample CUB1004 by a grain averaging effect (as observed in the OSL dating study), it is currently unclear whether this phenomenon would impact the ESR results to the same extent. The information available regarding single grain behavior in ESR dating is very limited. Recent attempts at undertaking single grain ESR measurements using Q band ESR spectrometry (e.g. Beerten and Stesmans, 2006) have shown that grains may indeed exhibit very different behaviors with irradiation dose, ranging from a clear increase (e.g., linear, exponential or saturating exponential) to an almost stochastic response (see Fig. 5 from Beerten and Stesmans, 2006). This grain-to-grain variability may partially explain the scatter usually observed in multi-aliquot ESR DRCs. However, the proportions of grains that actually contribute to the main ESR signal measured with multigrain aliquots remains unknown, as does the proportion of those grains that show appropriate dose response characteristics $(\sim 5 \%$ for the Cuesta de la Bajada samples in OSL, see Arnold et al., 2016). Although single grain ESR measurement would provide additional useful information and may help to improve the accuracy of the method, such an approach is likely to have many practical limitations (time consuming measurements; difficulties of achieving repeatable measurements in the Q-band; the need for permanent access to a gamma irradiation source for single aliquot measurements), precluding routine implementation by the vast majority of the ESR dating laboratories around the world.

\subsection{Summary}

The Cuesta de la Bajada quartz grains show some unique features in comparison with the samples previously analysed by Duval and Guilarte (2015). For the moment it is unclear how these properties impact the final ESR ages. First, the quartz samples exhibit an exceptionally high content of Ti-H centres, enabling the possibility of obtaining a seemingly robust $\mathrm{D}_{\mathrm{E}}$ data set. Second, options $\mathrm{A}, \mathrm{B}, \mathrm{C}$ and $\mathrm{D}$ do not behave as usually reported for the Ti centres: instead of showing non-monotonic dose response behaviors, the ESR signals display an apparent saturation at high dose values.

The differences observed in the dose estimates from each centre may naturally raise some questions regarding the choice of the most appropriate signal for ESR dating. For a given sample, the Al centre provides systematically higher $\mathrm{D}_{\mathrm{E}}$ estimates in comparison with those derived from the Ti centres; though they sometimes yield consistent dose estimates. This suggests that the signal of the Al centre has not been fully reset during transportation. In contrast, the Ti-Li centre measured alone (option E) provides unexpectedly high, and unrealistic, $\mathrm{D}_{\mathrm{E}}$ estimates, which may mostly be explained by a poor goodness-of-fit. Both Ti-H and Ti-Li-H option D provide the most consistent results when compared with the single-grain OSL ages, although it is unclear which of these two options should be preferred from the available data.

The results presented in this study are fairly consistent with those obtained by Beerten and Stesmans (2006) and Beerten et al. (2006). These authors specifically mentioned the possibility of systematic bias in $\mathrm{D}_{\mathrm{E}}$ estimation when both $\mathrm{Ti}-\mathrm{Li}$ and $\mathrm{Ti}-\mathrm{H}$ centres are present in a given sample: Ti-Li centres appear to show $\mathrm{D}_{\mathrm{E}}$ overestimate in the presence of Ti-H centres, suggesting some connection/transfer between the two centres. In light of these observations, Beerten and Stesmans (2006) recommend the use of a total Ti centre concentration for the $\mathrm{D}_{\mathrm{E}}$ calculation, which could correspond here in first instance to either options D or F. In a previous study, Beerten et al.
(2006) compared OSL results (obtained using a multiple grain SAR approach) and ESR results (obtained using a MAR approach) for several samples from the Murray Basin (Australia). For the youngest samples (Late Pleistocene), the authors observed good agreement between the OSL age estimates and the ESR results derived from the Ti-H centre, whereas the Ti-Li centre seemed to provide systematic age overestimation. For older samples (Middle Pleistocene), the Ti-H seemed to yield age underestimation, while an option based on a total Ti concentration produced more consistent ages in comparison with the OSL results. It should also be mentioned that the thermal stability of the Ti-H centre is unknown in comparison with the other centres (see Toyoda and Ikeya, 1991), and the ability of this centre to accurately register dose values above $1000 \mathrm{~Gy}$ has also been questioned (Duval and Guilarte, 2015). For these reasons, it is for the moment quite unclear how the Ti-H signal would behave for chronologies $>300-400 \mathrm{ka}$, and any conclusions about this centre derived from the present study should in first instance not be extrapolated to samples older than the late Middle Pleistocene time range.

Consequently, these observations, combined with the lower robustness of the data derived from the Ti-H centre, would in the first instance indicate that the ESR chronology obtained using the Ti-Li-H centres (option D) is potentially more reliable at Cuesta de la Bajada. Regardless, these ESR results clearly demonstrate the importance of systematically and simultaneously measuring both the Al and Ti centres in a given sample. Additional ESR dating of fossil teeth from layer CB-3 is currently ongoing (Duval et al., 2016) and should provide additional semi-independent age control for this site.

\subsection{Refining the chronology of Cuesta de la Bajada}

Because OSL and ESR samples CUB1005 and CB10-2 were both collected from archaeological layer CB-3 and within the exact area of the excavation, they should therefore be considered as the most appropriate samples to assess the chronology of Cuesta de la Bajada site. Following the $\mathrm{MC}$ approach, the ESR results indicate that the intensity of the Al centre was probably not completely zeroed prior to sediment deposition. Consequently, the Al-ESR age of $416 \pm 44$ ka should be considered as a maximum possible age estimate for the archaeological layer. In this context, the ESR ages derived from the Ti centres provide more correct estimations of the true age of the site. Even though the Ti-centre ages of CUB1005 are consistent at one sigma, they differ by $\sim 25 \%$ (Fig. 8). Based on comparisons with OSL age estimates, Beerten et al. (2006) suggested the use of a total Ti-centre concentration, which would correspond to the option D age of $328 \pm 32 \mathrm{ka}$. However, it is worth noting here that the single grain OSL and Ti-H ESR age estimates of CUB1005 are in closest agreement at 1 sigma $(264 \pm 22$ and $247 \pm 29 \mathrm{ka}$, respectively).

According to Santonja et al. (2014), analysis of the micro- and large mammal assemblages indicates a transitional landscape between forest and prairies, and the proximity of water, which suggests a temperate climate at the time of human occupation. Consequently, Cuesta de la Bajada might be tentatively correlated to an interglacial stage, very likely either MIS 7 or 9 (Lisiecki, and Raymo, 2005).

\section{Conclusion}

Following on from the research undertaken on the Early Pleistocene deposits of the Alcanadre River (e.g., Duval et al., 2015a,b), this ESR dating study of the Middle Pleistocene site of Cuesta de la Bajada again demonstrates the usefulness of using the Multiple Centres approach. Although the Al centre can provide ESR ages that are stratigraphically consistent, it should routinely be interpreted as 
yielding maximum possible chronologies in the absence of associated Ti results or independent age control. It has now become obvious that the systematic measurement of both $\mathrm{Al}$ and Ti centres should be a minimum requirement in the analytical procedure of quartz ESR dating.

The numerical ages obtained at Cuesta de la Bajada show good overall consistency between the Ti-ESR signals and the equivalent single-grain OSL results. Given the unique characteristics of these quartz samples, it has been possible to derive an apparently robust chronology based on the Ti-H centre. These Ti-H ages are systematically younger than those provided by the Ti-Li-H (option D) centres but they are broadly consistent with the OSL age estimates. Direct comparison of the ESR/OSL dating results is made somewhat complicated by major differences in the analytical procedures; particularly regarding the number of grains used for $\mathrm{D}_{\mathrm{E}}$ analysis. From a methodological point of view, it seems important to further understand the behavior of the ESR signals at a single grain level and to investigate the impacts of averaging effects at a multi-grain scale. Regardless, the present ESR dating comparison reveals great potential for using $\mathrm{Ti}$ centres to date late Middle Pleistocene deposits.

\section{Acknowledgements}

Some of the data shown in the present study were derived from analysis covered by the project CGL2010-16821 from the Spanish Ministry of Science and Innovation. M. Duval's research was funded by a Marie Curie International Outgoing Fellowship of the EU's Seventh Framework Programme (FP7/2007-2013), awarded under REA Grant Agreement No. PIOF-GA-2013-626474. L. Arnold and M. Demuro were partly supported by Australian Research Council Future Fellowship grant FT130100195 and Discovery Early Career Researcher Award DE160100743, respectively, during the course of this study. Finally, we thank the two anonymous reviewers for their constructive comments.

\section{Appendix A. Supplementary data}

Supplementary data related to this article can be found at http://dx. doi.org/10.1016/j.quageo.2016.09.006.

\section{References}

Arlegui, L.E., Simón, J.L., Lisle, R.J., Orife, T., 2006. Analysis of non-striated faults in a recent extensional setting: the Plio-Pleistocene Concud fault (Jiloca graben, eastern Spain). J. Struct. Geol. 28 (6), 1019-1027.

Arnold, L.J., Demuro, M., 2015. Insights into TT-OSL signal stability from single-grain analyses of known-age deposits at Atapuerca, Spain. Quat. Geochronol. 30, 472-478.

Arnold, L.J., Demuro, M., Ruiz, Navazo, 2012. Empirical Insights into multi-grain averaging effects from 'pseudo' single-grain OSL measurements. Radiat. Meas. 47, 652-658.

Arnold, L.J., Demuro, M., Navazo Ruiz, M., Benito-Calvo, A., Pérez-González, A., 2013. OSL dating of the Middle Palaeolithic Hotel California site, Sierra de Atapuerca, north-central Spain. Boreas 42, 285-305.

Arnold, L.J., Demuro, M., Parés, J.M., Arsuaga, J.L., Aranburu, A., Bermúdez de Castro, J.M., Carbonell, E., 2014. Luminescence dating and palaeomagnetic age constraint on hominins from Sima de los Huesos, Atapuerca, Spain. J. Hum. Evol. 67, 85-107.

Arnold, L.J., Demuro, M., Parés, J.M., Pérez-González, A., Arsuaga, J.L., Bermúdez de Castro, J.M., Carbonell, E., 2015. Evaluating the suitability of extended-range luminescence dating techniques over Early and Middle Pleistocene timescales: published datasets and case studies from Atapuerca, Spain. Quat. Int. 389, 167-190.

Arnold, L.J., Duval, M., Demuro, M., Spooner, N.A., Santonja, M., Pérez-González, A., 2016. OSL dating of individual quartz 'supergrains' from the ancient Middle Palaeolithic site of Cuesta de la Bajada, Spain. Quat. Geochronol. 36, 78-101.
Bahain, J.-J., Falguères, C., Shao, Q., Tombret, O., Duval, M., Dolo, J.-M., 2015. La datation ESR/U-Th de restes paléontologiques, un outil pour estimer le possible remaniement des niveaux archéologiques?. Quaternaire 26 (3), 213-223.

Beerten, K., Stesmans, A., 2006. The use of Ti centers for estimating burial doses of single quartz grains: a case study from an aeolian deposit -2 Ma old. Radiat. Meas. 41 (4), 418-424.

Beerten, K., Lomax, J., Clémer, K., Stesmans, A., Radtke, U., 2006. On the use of Ti centres for estimating burial ages of Pleistocene sedimentary quartz: multiple-grain data from Australia. Quat. Geochronol. 1 (2), 151-158.

Beerten, K., Rittner, S., Lomax, J., Radtke, U., 2008. Dose recovery tests using Ti-related ESR signals in quartz: first results. Quat. Geochronol. 3 (1-2), 143-149.

Berger, G.W., Pérez-González, A., Carbonell, E., Arsuaga, J.L., Bermúdez de Castro, J.M., Ku, T.L., 2008. Luminescence chronology of cave sediments at the Atapuerca paleoanthropological site, Spain. J. Hum. Evol. 55 (2), 300-311.

Bøtter-Jensen, L., Mejdahl, V., 1988. Assessment of beta dose-rate using a GM multicounter system. Nucl. Tracks Radiat. Meas. 14.

Brennan, B.J., Lyons, R.G., Phillips, S.W., 1991. Attenuation of alpha particle track dose for spherical grains. Nucl. Tracks Radiat. Meas. 18, 249-253.

Brennan, B.J., 2003. Beta doses to spherical grains. Radiat. Meas. 37, 299-303.

Burdette, K.E., Rink, W.J., Mallinson, D.J., Means, G.H., Parham, P.R., 2013. Electron spin resonance optical dating of marine, estuarine, and aeolian sediments in Florida, USA. Quat. Res. 79 (1), 66-74.

Cordier, S., Harmand, D., Lauer, T., Voinchet, P., Bahain, J.-J., Frechen, M., 2012. Geochronological reconstruction of the Pleistocene evolution of the Sarre valley (France and Germany) using OSL and ESR dating techniques. Geomorphology 165-166 (0), 91-106.

Cuenca-Bescós, G., Rofes, J., López-García, J.M., Blain, H.-A., De Marfá, R.J., Galindo-Pellicena, M.A., Bennásar-Serra, M.L., Melero-Rubio, M., Arsuaga, J.L., Bermúdez de Castro, J.M., Carbonell, E., 2010. Biochronology of Spanish quaternary small vertebrate faunas. Quat. Int. 212 (2), 109-119.

Cuenca-Bescós, G., LÓPez-GarcíA, J.M., Galindo-Pellicena, M.A., GarcíA-Perea, R., Gisbert, J., Rofes, J., Ventura, J., 2014. Pleistocene history of Iberomys, an endangered endemic rodent from southwestern Europe. Integr. Zool. 9 (4), 481-497.

Demuro, M., Arnold, L.J., Parés, J.M., Pérez-González, A., Ortega, A.I., Arsuaga, J.L., Bermúdez de Castro, J.M., Carbonell, E., 2014. New luminescence ages for the Galería complex archaeological site: resolving chronological uncertainties on the Acheulean record of the Sierra de Atapuerca, northern Spain. PLoS One 9 (10), e110169.

Demuro, M., Arnold, L.J., Parés, J.M., Sala, R., 2015. Extended-range luminescence chronologies suggest potentially complex bone accumulation histories at the early-to-Middle Pleistocene palaeontological site of Huéscar-1 (Guadix-Baza basin, Spain). Quat. Int. 389, 191-212.

Despriée, J., Voinchet, P., Tissoux, H., Bahain, J.-J., Falguères, C., Courcimault, G., Dépont, J., Moncel, M.-H., Robin, S., Arzarello, M., Sala, R., Marquer, L., Messager, E., Puaud, S., Abdessadok, S., 2011. Lower and Middle Pleistocene human settlements recorded in fluvial deposits of the Middle Loire river basin, centre region, France. Quat. Sci. Rev. 30 (11-12), 1474-1485.

Domínguez-Rodrigo, et al., 2015. Another window to the subsistence of Middle Pleistocene hominins in Europe: a taphonomic study of Cuesta de la Bajada (Teruel, Spain). Quat. Sci. Rev. 126, 67-95.

Duval, M., 2008. Evaluation du Potentiel de la méthode de datation par Résonance de Spin Electronique (ESR) appliquée aux gisements du Pléistocène inférieur : étude des gisements d'Orce (bassin de Guadix-Baza, Espagne) et Contribution à la connaissance des Premiers Peuplements de l'Europe. Prehistory. Muséum National d'Histoire Naturelle, Paris. PhD: 522.

Duval, M., 2012. Dose response curve of the ESR signal of aluminum center in quartz grains extracted from sediment. Anc. TL 30 (2), 1-9.

Duval, M., Guilarte Moreno, V., 2012. Assessing the influence of the cavity temperature on the ESR signal of aluminum center in quartz grains extracted from sediment. Anc. TL 30 (2), 11-16.

Duval, M., Arnold, L.J., 2013. Field gamma dose-rate assessment in natural sedimentary contexts using $\mathrm{LaBr} 3(\mathrm{Ce})$ and $\mathrm{NaI}(\mathrm{Tl})$ probes: a comparison between the "threshold" and "windows" techniques. Appl. Radiat. Isot. 74 (0), 36-45.

Duval, M., Grün, R., Falguères, C., Bahain, J.-J., Dolo, J.-M., 2009. ESR dating of Lower Pleistocene fossil teeth: limits of the single saturating exponential (SSE) model for the equivalent dose determination. Radiat. Meas. 44, 477-482.

Duval, M., Guilarte, V., 2015. ESR dosimetry of optically bleached quartz grains extracted from Plio-quaternary sediment: evaluating some key aspects of the ESR signal associated to the Ti-center. Radiat. Meas. 78, 28-41.

Duval, M., Falguères, C., Bahain, J.-J., Grün, R., Shao, Q., Aubert, M., Dolo, J.-M., Agustí, J., Martínez-Navarro, B., Palmqvist, P., Toro-Moyano, I., 2012. On the limits of using combined U-series/ESR method to date fossil teeth from two early pleistocene archaeological sites of the Orce area (Guadix-Baza basin, Spain). Quat. Res. 77 (3), 482-491.

Duval, M., Bahain, J.-J., Falguères, C., Garcia, J., Guilarte, V., Grün, R., Martínez, K., Moreno, D., Shao, Q., Voinchet, P., 2015a. Revisiting the ESR chronology of the 
early Pleistocene hominin occupation at Vallparadís (Barcelona, Spain). Quat. Int. 389, 213-223.

Duval, M., Sancho, C., Calle, M., Guilarte, V., Peña-Monné, J.L., 2015b. On the interest of using the multiple center approach in ESR dating of optically bleached quartz grains: some examples from the Early Pleistocene terraces of the Alcanadre river (Ebro basin, Spain). Quat. Geochronol. 29, 58-69. http://dx.doi.org/10.1016/ j.quageo.2015.06.006

Duval, M., Grün, R., Shao, Q., Martin, L., Arnold, L., Santonja, M., Pérez-Gonzalez, A., 2016. Electron Spin Resonance dating of fossil teeth at Cuesta de la Bajada site (Spain): some insight into intra- and inter-sample variability. Oral communication. In: AFEQ-Q10 Conference (Bordeaux, France), 16-18/02/2016.

Falguères, C., Bahain, J.-J., Yokoyama, Y., Arsuaga, J.L., Bermudez de Castro, J.M., Carbonell, E., Bischoff, J.L., Dolo, J.-M., 1999. Earliest humans in Europe: the age of TD6 Gran Dolina, Atapuerca, Spain. J. Hum. Evol. 37 (3-4), 343-352.

Galbraith, R.F., 2002. A note on the variance of a background corrected OSL count. Anc. TL 20, 49-51.

Gao, L., Yin, G.-M., Liu, C.-R., Bahain, J.-J., Lin, M., Li, J.-P., 2009. Natural sunlight bleaching of the ESR titanium center in quartz. Radiat. Meas. 44 (5-6), 501-504.

Guérin, G., Mercier, N., Adamiec, G., 2011. Dose-rate conversion factors: update. Anc. TL 29 (1), 5-8.

Grün, R., 1994. A cautionary note: use of 'water content' and 'depth for cosmic ray dose rate' in AGE and DATA programs. Anc. TL 12 (2), 50-51.

Gutiérrez, F., Gutiérrez, M., Gracia, F.J., McCalpin, J.P., Lucha, P., Guerrero, J., 2008. Plio-Quaternary extensional seismotectonics and drainage network development in the central sector of the Iberian Chain (NE Spain). Geomorphology 102 (1), $21-42$.

Liu, C.-R., Grün, R., 2011. Fluvio-mechanical resetting of the $\mathrm{Al}$ and Ti centres in quartz. Radiat. Meas. 46 (10), 1038-1042.

Liu, C.-R., Yin, G.-M., Fang, F., Voinchet, P., Deng, C.-L., Han, F., Li, J.-P., Song, W.-J., Wang, D., Bahain, J.-J., 2013. ESR dating of the Donggutuo Palaeolithic site in the Nihewan basin, northern China. Geochronometria 40 (4), 348-354.

Lisiecki, L.E., Raymo, M.E., 2005. A Pliocene-Pleistocene stack of 57 globally distributed benthic $\delta 180$ records. Paleoceanography 20 (1) (n/a-n/a).

Parés, J.M., Arnold, L., Duval, M., Demuro, M., Pérez-González, A., Bermúdez de Castro, J.M., Carbonell, E., Arsuaga, J.L., 2013. Reassessing the age of Atapuerca-TD6 (Spain): new paleomagnetic results. J. Archaeol. Sci. 40 (12), 4586-4595.

Prescott, J.R., Hutton, J.T., 1988. Cosmic ray and gamma ray dosimetry for TL and ESR. Nucl. Tracks Radiat. Meas. 14, 223-227.

Prescott, J.R., Hutton, J.T., 1994. Cosmic ray contributions to dose rates for luminescence and ESR dating: large depths and long-term time variations. Radiat. Meas. 23, 497-500.

Preusser, F., Chithambo, M.L., Götte, T., Martini, M., Ramseyer, K., Sendezera, E.J., Susino, G.J., Wintle, A.G., 2009. Quartz as a natural luminescence dosimeter. Earth Sci. Rev. 97 (1-4), 184-214.

Rixhon, G., Briant, B., Cordier, S., Duval, M., Jones, A., Scholz, D., 2016. Setting the pace of river landscape evolution at different timescales during the quaternary: recent developments in numerical dating methods. Quat. Sci. Rev. http://dx.doi.org/ 10.1016/j.quascirev.2016.08.016.

Rink, W.J., Bartoll, J., Schwarcz, H.P., Shane, P., Bar-Yosef, O., 2007. Testing the reliability of ESR dating of optically exposed buried quartz sediments. Radiat. Meas. 42 (10), 1618-1626.

Rodríguez, J., Burjachs, F., Cuenca-Bescós, G., García, N., Van der Made, J., Pérez González, A., Blain, H.A., Expósito, I., López-García, J.M., García Antón, M.,
Allué, E., Cáceres, I., Huguet, R., Mosquera, M., Ollé, A., Rosell, J., Parés, J.M., Rodríguez, X.P., Díez, C., Rofes, J., Sala, R., Saladié, P., Vallverdú, J., Bennasar, M.L., Blasco, R., Bermúdez de Castro, J.M., Carbonell, E., 2011. One million years of cultural evolution in a stable environment at Atapuerca (Burgos, Spain). Quat. Sci. Rev. 30 (11-12), 1396-1412.

Santonja, M., Pérez-González, A., 2000. La ocupación humana de la vertiente mediterránea ibérica en el Pleistoceno Medio. BSAA LXIV 9-23.

Santonja, M., Pérez-González, A., Domínguez-Rodrigo, M., Sesé, C., Soto, E., Panera, J., Rubio-Jara, S., Arnold, L.J., Duval, M., Demuro, M., Ortiz, J.E., de Torres, T., Mercier, N., Barba, R., Yravedra, J., 2014. The Middle Palaeolithic site of Cuesta de la Bajada (Teruel, Spain): a perspective on the Acheulean and Middle Paleolithic technocomplexes in Europe. J. Archaeol. Sci. 49, 556-571.

Tissoux, H., Falguères, C., Voinchet, P., Toyoda, S., Bahain, J.J., Despriée, J., 2007. Potential use of Ti-center in ESR dating of fluvial sediment. Quat. Geochronol. 2 (1-4), 367-372.

Tissoux, H., Toyoda, S., Falguères, F., Voinchet, P., Takada, M., Bahain, J.-J., Despriée, J., 2008. ESR dating of sedimentary quartz from two Pleistocene deposits using $\mathrm{Al}$ and Ti-centers. Geochronometria 30, 23-31.

Tissoux, H., Valladas, H., Voinchet, P., Reyss, J.L., Mercier, N., Falguères, C., Bahain, J.J., Zöller, L., Antoine, P., 2010. OSL and ESR studies of Aeolian quartz from the Upper Pleistocene loess sequence of Nussloch (Germany). Quat. Geochronol. 5 (2-3), 131-136.

Tissoux, H., Voinchet, P., Lacquement, F., Prognon, F., Moreno, D., Falguères, C., Bahain, J.-J., Toyoda, S., 2012. Investigation on non-optically bleachable components of ESR aluminium signal in quartz. Radiat. Meas. 47 (9), 894-899.

Toyoda, S., Ikeya, M., 1991. Thermal stabilities of paramagnetic defect and impurity centers in quartz: basis for ESR dating of thermal history. Geochem. J. $25,437-445$.

Toyoda, S., Falguères, C., 2003. The method to represent the ESR signal intensity of the aluminium hole center in quartz for the purpose of dating. Adv. ESR Appl. 20, 7-10.

Toyoda, S., Voinchet, P., Falguères, C., Dolo, J.M., Laurent, M., 2000. Bleaching of ESR signals by the sunlight: a laboratory experiment for establishing the ESR dating of sediments. Appl. Radiat. Isot. 52 (5), 1357-1362.

Vandenberghe, D., De Corteb, F., Buylaert, J.P., Kucera, J., y Van den haute, P., 2008. On the internal radioactivity in quartz. Radiat. Meas. 43, 771-775.

Voinchet, P., Falguères, C., Laurent, M., Toyoda, S., Bahain, J.J., Dolo, J.M., 2003. Artificial optical bleaching of the aluminium center in quartz implications to ESR dating of sediments. Quat. Sci. Rev. 22 (10-13), 1335-1338.

Voinchet, P., Falguères, C., Tissoux, H., Bahain, J.-J., Despriée, J., Pirouelle, F., 2007. ESR dating of fluvial quartz: estimate of the minimal distance transport required for getting a maximum optical bleaching. Quat. Geochronol. 2 (1-4), 363-366.

Voinchet, P., Yin, G., Falguères, C., Liu, C., Han, F., Sun, X., Bahain, J.J., 2013. ESR dose response of $\mathrm{Al}$ center measured in quartz samples from the Yellow river (China): implications for the dating of upper Pleistocene sediment. Geochronometria 40 (4), 341-347.

Walther, R., Zilles, D., 1994. ESR studies on bleached sedimentary quartz. Quat. Sci. Rev. 13 (5-7), 611-614.

Woda, C., Wagner, G.A., 2007. Non-monotonic dose dependence of the Ge- and Ti-centres in quartz. Radiat. Meas. 42 (9), 1441-1452.

Yokoyama, Y., Falgueres, C., Quaegebeur, J.P., 1985. ESR dating of quartz from quaternary sediments: first attempt. Nucl. Tracks Radiat. Meas. (1982) 10 (4-6), 921-928. 